\title{
D- $\pi$-A compounds with tunable intramolecular charge transfer achieved by incorporation of butenolide nitriles as acceptor moieties
}

Carlos Moreno-Yruela, ${ }^{\dagger}$ Javier Garín, ${ }^{\dagger}$ Jesús Orduna, ${ }^{\dagger}$ Santiago Franco, $^{\dagger}$ Estefanía Quintero, ${ }^{\ddagger}$ Juan T. López Navarrete, ${ }^{\ddagger}$ Beatriz E. Diosdado, ${ }^{\S}$ Belén Villacampa," Juan Casado** $^{\ddagger}$ and Raquel Andreu* ${ }^{\dagger}$

† Departamento de Química Orgánica, ICMA, Universidad de Zaragoza-CSIC, 50009 Zaragoza, Spain.

‡ Departamento de Química Física, Universidad de Málaga, Campus de Teatinos s/n, 29071 Málaga, Spain.

§ Servicio de Rayos X y Análisis por Fluorescencia, Universidad de Zaragoza, 50009 Zaragoza, Spain.

|| Departamento de Física de la Materia Condensada, ICMA, Universidad de ZaragozaCSIC, 50009 Zaragoza, Spain.

Corresponding author’s e-mail address: randreu@unizar.es; casado@uma.es

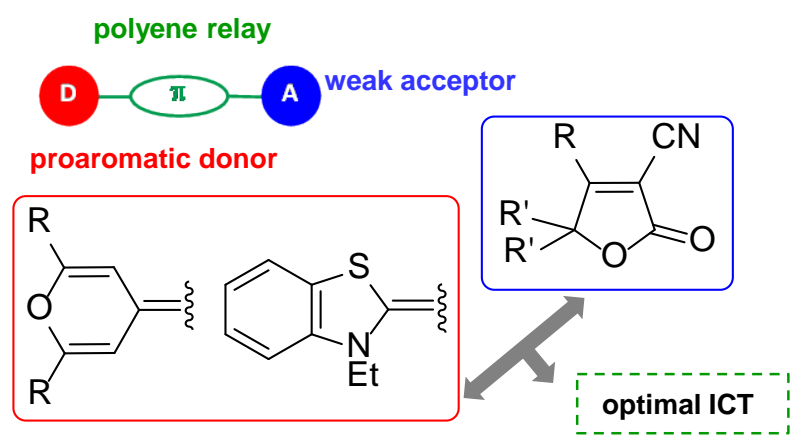
Abstract
Chromophores where a polyenic spacer separates a $4 H$-pyranylidene or benzothiazolylidene donor and three different butenolide nitriles have been synthesized and characterized. The role of $2(5 H)$-furanones as acceptor units on the polarization and the 
second-order nonlinear (NLO) properties has been studied. Thus, their incorporation gives rise to moderately-polarized structures with NLO responses which compare favorably to those of related compounds featuring more efficient electron-withdrawing moieties. Derivatives of the proaromatic butenolide $\mathbf{P h F u}$ show the best nonlinearities. Benzothiazolylidene-containing chromophores present less alternated structures than their pyranylidene analogues, and, unlike most merocyanines, the degree of charge transfer does not decrease on lengthening the $\pi$-bridge.

\section{Introduction}

Push-pull organic chromophores, in which a $\pi$-conjugated bridge is end-capped by a donor (D) and an acceptor (A), constitute a blueprint in the search for new materials endowed with nonlinear optical (NLO) properties and have been extensively studied because of their technological and fundamental interest. ${ }^{1}$ In such $\mathrm{D}-\pi$-A arrangement, efficient intramolecular charge transfer (ICT) from the donor to the acceptor takes place and the molecules become polarized. Microscopically, the second-order nonlinearity of chromophores can be represented by the scalar product of the vector part of the hyperpolarizability tensor $(\beta)$ and the dipole moment $(\mu)$.

The extent of the ICT can be finely tuned by variations of particular D, $\pi$ and A components of a push-pull molecule, and this has been demonstrated to be crucial in order to maximize the second-order NLO response. In this way, general structure-activity relationships have been established. ${ }^{2}$

In simple valence bond language, $\mathrm{D}-\pi$-A systems can be represented by two extreme limiting forms: neutral (N) and zwitterionic (ZW) with an intermediate situation corresponding to the so-called “cyanine limit” (CL). (Scheme 1) 


\section{Scheme 1. Canonical forms for a D- $\pi$-A system.}

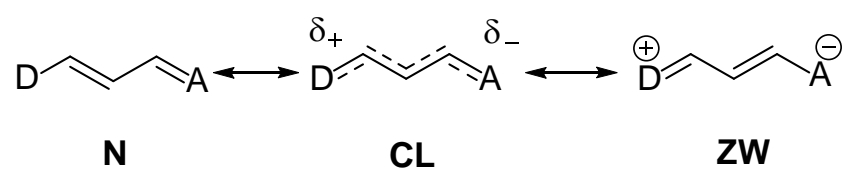

According to this model, it is possible to maximize $\beta$ by optimizing the contribution of the neutral and the charge-separated canonical forms to the ground state of the molecule. This mixing can be evaluated through the bond length alternation (BLA) value, defined as the difference between the average $\mathrm{C}-\mathrm{C}$ single and multiple bond lengths in the conjugated backbone. $^{3}$ In chromophores with weak $\mathrm{D}$ and A groups, $\beta$ is positive. As the molecular polarization progressively increases (for instance by using stronger $\mathrm{D}$ or $\mathrm{A}$ ends) $\beta$ increases, peaks in a positive sense, and then decreases, crosses through zero at the cyanine limit, and then becomes negative when the ground state of the molecule becomes zwitterionic. The rationalization of this behavior (Marder's plot) ${ }^{3 b}$ has allowed the establishment of very useful guidelines for the design of NLO chromophores. ${ }^{4}$

Most frequently, in search of the optimization of the $\beta$ value, modern push-pull molecules are equipped with strong D/A units, and single acceptors (like formyl, cyano or nitro groups) ${ }^{5}$ are less used. However, weak acceptors could provide high nonlinearities when combined with a strong donor and an efficient $\pi$-relay.

$\Delta^{\alpha, \beta}$-butenolides (or 2(5H)-furanones) ${ }^{6}$ (Scheme 2(a)) constitute an important class of natural products ${ }^{7}$ among which the best known is vitamin C. Although they have been deeply studied because of their biological applications, this type of heterocycle has been scarcely used in the field of NLO: on the experimental side, the only studies were reported by Chang et al., ${ }^{8 a}$ who studied the NLO response of a merocyanine bearing a benzothiazole unit as donor. Authors indicate that this dye is a one-dimensional chromophore with an 
important $\mu \beta$ value measured by solvatochromic methods and, on the other hand, on a derived LB film. Theoretical calculations also confirm their NLO activity. ${ }^{8}$

Scheme 2. (a) General structure of a 2,3,4,4-tetrasubstituted but-2-ene-4-olide; (b) structures of but-2-ene-4-olide nitriles used in this work.

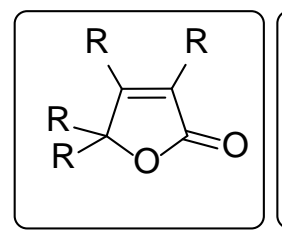

(a)

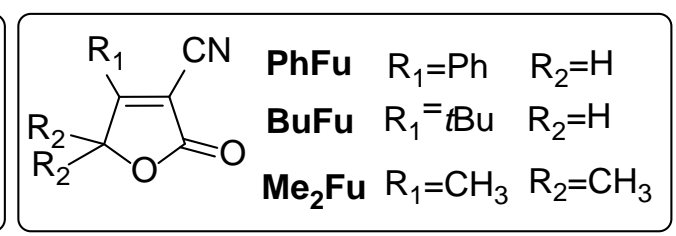

(b)

Butenolide nitriles, with a cyano group in C2 (Scheme 2(b)) could act as weak electronwithdrawing units and, depending on the substitution, offer a double alternative: (i) reacting by the $\mathrm{C} 4$ (Scheme 2(b); $\mathrm{R}_{2}=\mathrm{H}$ ) they would be incorporated to the chromophore as proaromatic ${ }^{4 a}$ acceptors; (ii) reacting by the $\mathrm{R}_{1}$ position (Scheme 2(b)) they would be linked to the $\pi$-spacer as non-proaromatic acceptors and could be considered as a "weak version" of the widely used 2-dicyanomethylene-3-cyano-4,5,5-trimetyl-2,5-hydrofuran (TCF) acceptor. $^{9}$

In this context, we have turned our attention to the study of D- $\pi$-A compounds with 2(5H)-furanones as electron-withdrawing moieties, having second-order NLO responses. Thus, three butenolide-type acceptors have been chosen for this work (Scheme 2(b)): compounds $\mathbf{P h F u}$ and $\mathbf{B u F u}$ are proaromatic acceptors and differ on the $\mathrm{R}_{1}$ substituent: a phenyl (PhFu) or a tert-butyl group (BuFu). The latter have a double purpose: first, to disclose the effect of an inductive-donor and bulky substituent on the electron-withdrawing unit, and second, to increase the solubility of the final chromophores. 2(5H)-furanone $\mathbf{M e}_{2} \mathbf{F u}$ is a non proaromatic acceptor. Overall, this will allow to evaluate the effect that the 
quinoid or non-quinoid character of the acceptor moiety has on the molecular polarization and on the NLO response of the final D- $\pi$-A systems.

With the aim of ensuring an effective molecular polarization, compounds $\mathbf{P h F u}, \mathbf{M e}_{2} \mathbf{F u}$, BuFu have been combined (Scheme 3) with a polyene relay and two proaromatic electrondonor moieties: $4 H$-pyranylidene ${ }^{10}$ (series Py) and benzothiazolylidene ${ }^{11}$ (series $\mathbf{B z}$ ). The latter fragment has also been studied as acceptor ${ }^{12}$ or $\pi$-spacer ${ }^{13}$ in chromophores with NLO properties.

For the sake of clarity, target compounds (Scheme 3) have been named beginning with $\mathbf{P y}$ or $\mathbf{B z}$, in order to indicate the donor, followed by a number ( $\mathbf{0}$ or $\mathbf{1})$ that denotes the length of the $\pi$-spacer and $\mathbf{P h F u}, \mathbf{M e}_{2} \mathbf{F u}, \mathbf{B u F u}$ that concerns the butenolide ring. 
Scheme 3. Structures of the target compounds.

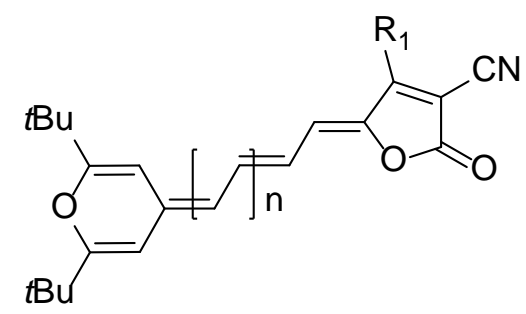

PyOPhFu $\mathrm{n}=0 \quad \mathrm{R}_{1}=\mathrm{Ph}$

Py1PhFu $n=1 \quad R_{1}=P h$

Py0BuFu $n=0 \quad \mathrm{R}_{1}{ }^{=} t \mathrm{Bu}$

Py1BuFu $n=1 \quad R_{1}{ }^{=} t B u$<smiles>[R1]C1=C(C#N)C(=O)O/C1=C\C=C/C=C\C=C1/Nc2ccccc2S1</smiles>

BzOPhFu $n=0 \quad R_{1}=P h$

Bz1PhFu $n=1 \quad R_{1}=P h$

BzOBuFu $n=0 \quad \mathrm{R}_{1}{ }^{=} t \mathrm{Bu}$

Bz1BuFu $n=1 \quad R_{1}{ }^{*} t B u$

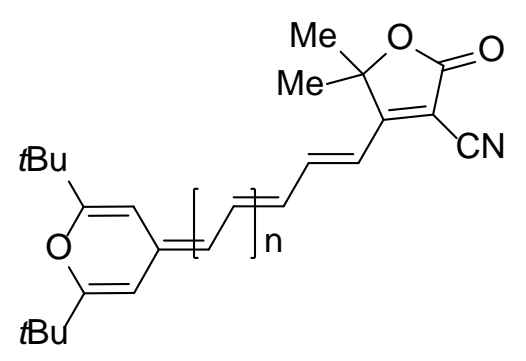

$\mathrm{PyOMe}_{2} \mathrm{Fu} \quad \mathrm{n}=0$

Py1Me2 Fu $n=1$

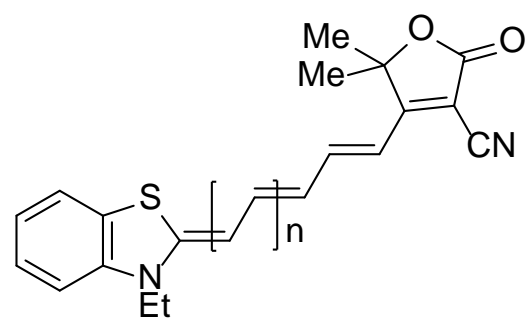

$\mathrm{BzOMe}_{2} \mathrm{Fu} \quad \mathrm{n}=0$

$\mathrm{Bz1Me}_{2} \mathrm{Fu} \quad \mathrm{n}=1$

A detailed investigation of the ICT existent in these chromophores by using different techniques, together with the measurement of their $\mu \beta$ figure of merit is presented throughout this paper.

\section{Results and Discussion}

Synthesis. The synthesis of acceptors $\mathbf{P h F u , ~} \mathbf{M e}_{2} \mathbf{F u}, \mathbf{B u F u}$ was previously reported ${ }^{14-16}$ with a different method for each butenolide. Our attempts to prepare BuFu according a previously described method ${ }^{16}$ led to the desired compound, but not with successful yield. Then, for this work, compound BuFu was synthesized by following the experimental protocol used for PhFu (Scheme 4), starting from 1-bromopinacolone and cyanoacetic 
acid, and was been fully characterized. During this synthesis, the corresponding oxocyanoacetate $\mathbf{1}$ was also isolated and characterized. Subsequent cyclization of $\mathbf{1}$ in the presence of base afforded another portion of furanone BuFu. (Scheme 4)

\section{Scheme 4. Synthesis of butenolide nitrile BuFu.}
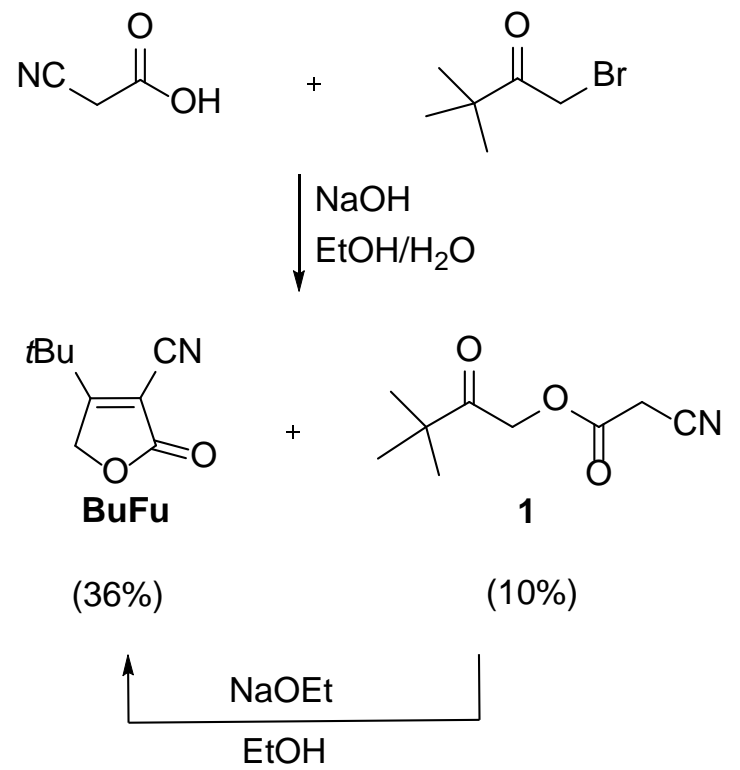

$(20 \%)$

For series Py, the Knoevenagel reaction between acceptors $\mathbf{P h F u}, \mathbf{M e}_{2} \mathbf{F u}, \mathbf{B u F u}$ and pyranylidene-containing aldehydes $\mathbf{P y 0}-\mathbf{P y} \mathbf{1}^{17,10 \mathrm{~b}}$ in EtOH afforded the new D- $\pi$-A chromophores $\mathbf{P y 0}\left(\mathbf{P h F u}, \mathbf{M e}_{2} \mathbf{F u}, \mathbf{B u F u}\right)$ and $\mathbf{P y 1}\left(\mathbf{P h F u}, \mathbf{M e}_{2} \mathbf{F u}, \mathbf{B u F u}\right)$ in yields that ranged from 20 to $69 \%$. (Scheme 5) For the reactions involving furanone $\mathbf{M e}_{2} \mathbf{F u}$, the addition of one drop of piperidine was needed. It is noteworthy that yields for derivatives Py0(PhFu, Me $2 \mathrm{Fu}, \mathrm{BuFu})$ were considerably higher than for their vinylogues $\operatorname{Py} 1\left(\mathbf{P h F u}, \mathrm{Me}_{2} \mathbf{F u}, \mathbf{B u F u}\right)$. This is due to the fact that during the synthesis of the latter, small amounts of $\mathbf{P y} 0\left(\mathbf{P h F u}, \mathbf{M e}_{2} \mathbf{F u}, \mathbf{B u F u}\right)$ are formed as a consequence of a vinyleneshortening reaction that has already been reported for other Knoevenagel-type reactions by us $^{18}$ and other authors. ${ }^{19}$ 
Scheme 5. Synthesis of pyranylidene-containing chromophores Py0(PhFu,Me $\left.\mathrm{Fu}_{2} \mathrm{BuFu}\right)$ and Py1(PhFu,Me $\left.\mathrm{Fu}_{2} \mathrm{BuFu}\right)$.

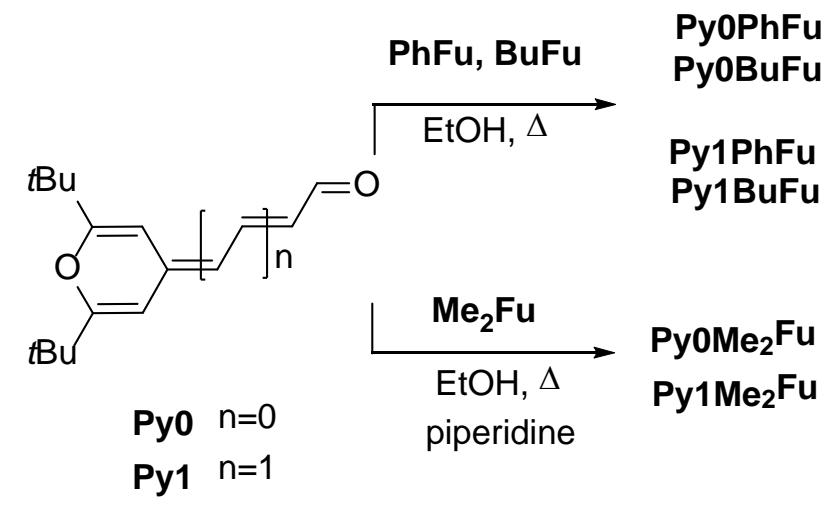

Concerning compounds $\mathrm{BzO}\left(\mathrm{PhFu}, \mathrm{Me}_{2} \mathrm{Fu}, \mathrm{BuFu}\right)$ and $\mathrm{Bz1}\left(\mathrm{PhFu}, \mathrm{Me}_{2} \mathrm{Fu}, \mathrm{BuFu}\right)$, they were synthesized as shown in Scheme 6, by reaction of iminium salts $\mathbf{B z 0}-\mathbf{B z 1}^{20}$ with the corresponding acceptors $\mathbf{P h F u}, \mathbf{M e}_{2} \mathbf{F u}, \mathbf{B u F u}$ in the presence of triethylamine. In this series no vinylene-shortening degradation was detected.

Scheme 6. Synthesis of benzothiazolylidene-containing chromophores $\mathrm{BzO}\left(\mathrm{PhFu}, \mathrm{Me}_{2} \mathrm{Fu}, \mathrm{BuFu}\right)$ and Bz1(PhFu,Me $\left.\mathrm{Fu}, \mathrm{BuFu}\right)$.

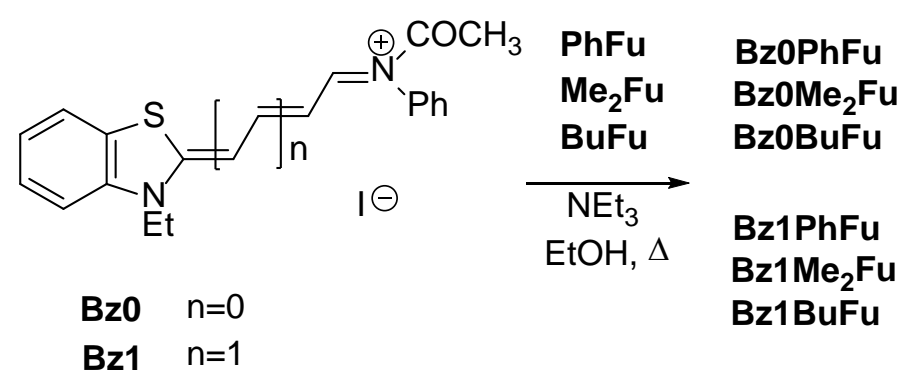

The synthesis of compound $\mathbf{B z 0 P h F u}$ had already been reported ${ }^{14}$ using piperidine as base, but not fully characterized. Moreover, its NLO response had been previously studied by other authors ${ }^{8 a}$ as mentioned in the Introduction. 
Structural characterization by X-ray crystallography. Single crystals of compounds Py0PhFu, Py1PhFu and Py1Me $\mathrm{M}_{2} \mathbf{F u}$ were obtained by slow diffusion of hexane into a solution of the corresponding chromophore in $\mathrm{CH}_{2} \mathrm{Cl}_{2}$ at room temperature. Four crystallographically independent molecules are found in the asymmetric unit cell of Py0PhFu (Figure 1), while those of Py1PhFu and $\mathbf{P y}_{\mathbf{M}} \mathbf{M e}_{2} \mathbf{F u}$ both contain a single molecule. (Figure 2)

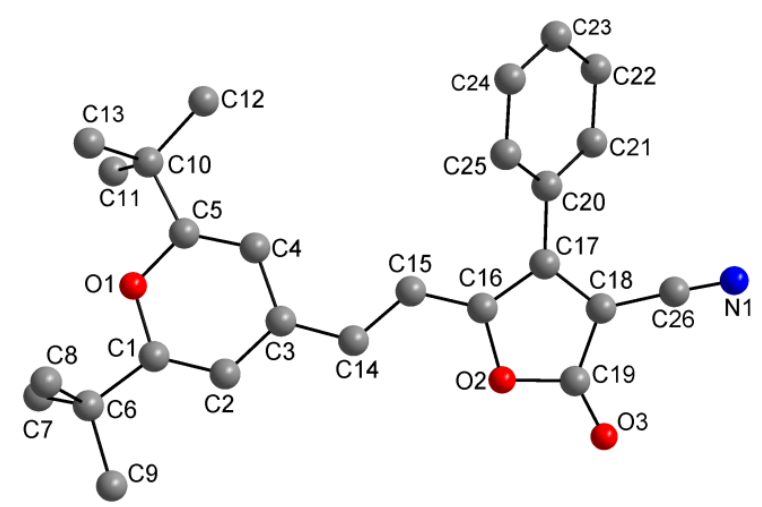

Figure 1. Molecular structure of compound Py0PhFu. (For clarity, only one molecule is shown. See Figure S-38 for viewing the four molecules found in the asymmetric unit cell)

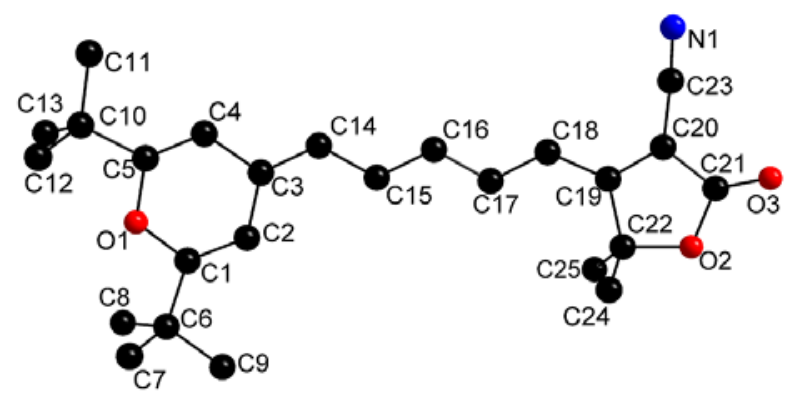




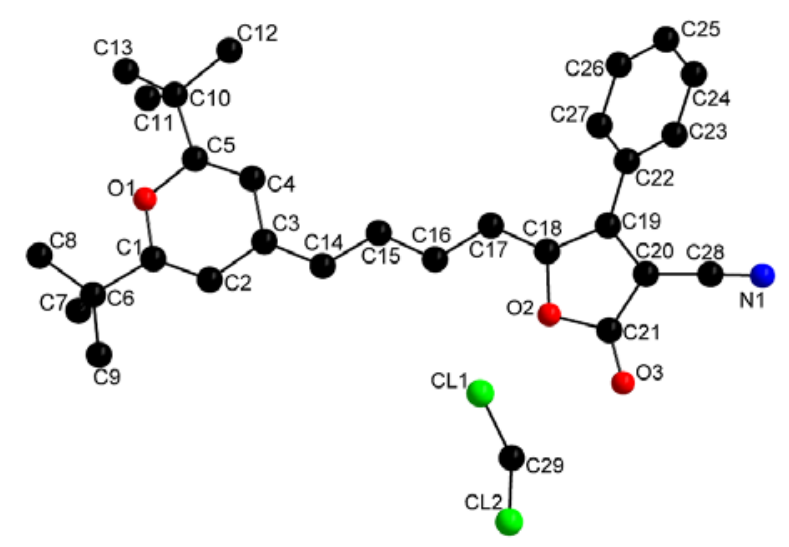

Figure 2. Molecular structures of compounds Py1PhFu, which crystallizes with a molecule of $\mathrm{CH}_{2} \mathrm{Cl}_{2}$ (bottom), and $\mathbf{P y 1} \mathbf{M e}_{2} \mathbf{F u}$ (top).

The analysis of the solid state structures can provide useful information about how the ground electronic state polarization varies when modifying the character of the butenolide group or lengthening the spacer.

There are some main features shared by the three structures: (i) the D- $\pi$-A system is essentially planar with the following angles between the mean planes of the pyran and the butenolide rings (Py0PhFu: $17.3^{\circ}, 6.0^{\circ}, 16.9^{\circ}, 6.0^{\circ}$, Py1PhFu: 5.5 ${ }^{\circ}, \mathbf{P y 1 M e} \mathbf{F u}_{2} 1^{\circ}$ ); (ii) the phenyl substituent in Py0PhFu-Py1PhFu is not coplanar with the butenolide moiety (dihedral angles: $37.4^{\circ}, 45^{\circ}, 36.7^{\circ}$ and $44.6^{\circ}$ for the four molecules in Py0PhFu and $33.3^{\circ}$ in Py1PhFu); (iii) the polyenic chain has an all-trans geometry except for the formal double bond connecting the $\pi$-spacer with the acceptor unit in Py0PhFu-Py1PhFu, with a $Z$ configuration.

Some structural parameters of the pyranylidene ring, including BLA value along the spacer (Figure 3) reveal the ground electronic state polarization from the donor end of the chromophore to the acceptor group. 


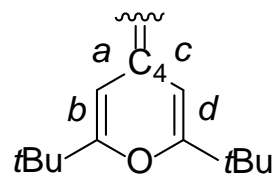

Bond lengths involved in the calculation of $\delta r$

\begin{tabular}{cccccc}
\hline Compd & $\mathrm{C}_{-} \mathrm{O}^{a}$ & $\mathrm{C}_{4}-\mathrm{C}_{\mathrm{exo}}{ }^{a}$ & $\delta r$ & $I_{6}$ & $\mathrm{BLA}^{a}$ \\
\hline Py0PhFu $^{b}$ & 1.372 & 1.391 & 0.094 & 34.2 & 0.023 \\
Py1PhFu & 1.374 & 1.386 & 0.098 & 32.3 & 0.030 \\
Py1Me $2 \mathrm{Fu}$ & 1.374 & 1.354 & 0.113 & 27.8 & 0.056 \\
\hline
\end{tabular}

${ }^{a}$ Bond lenght in $\AA$

${ }^{b}$ Average values for the four molecules

Figure 3. Structural parameters for the pyranylidene donor and BLA values.

Then, for compounds Py0PhFu-Py1PhFu, a shortening of C-O bond, together with a lengthening of the pyran exocyclic bond and a decreased degree of $\mathrm{C}-\mathrm{C}$ bond alternation (evaluated through the parameter $\delta \mathrm{r},{ }^{21} \delta \mathrm{r}=(\mathrm{a}-\mathrm{b}+\mathrm{c}-\mathrm{d}) / 2 ; \delta \mathrm{r}=0$ for benzene and 0.10 for fully quinoid rings) was found. Moreover, the Bird index $\left(I_{6}\right)^{22}$ of the donor (Figure 3), used as an estimation of the aromaticity of the ring $\left(I_{6}=25.4\right.$ for fully quinoid pyrans; $I_{6}=50$ for pyrylium cations ${ }^{10 b}$ ) also indicates the partial contribution of the zwitterionic form to the ground electronic state of derivatives Py0PhFu-Py1PhFu.

Furthermore, comparison of structural parameters (Figure 3) shows that compound Py0PhFu presents a more polarized structure than its vinilogue Py1PhFu.

Comparison with X-ray structures of merocyanines bearing other acceptors could be instructive to get more information about the ground electronic state polarization of the studied systems. For instance, analogues of Py0PhFu/Py1PhFu with 3-phenyl-5isoxazolone $^{10 \mathrm{~b}} / 1,1,3$-tricyano-2-phenylpropene $\mathrm{p}^{10 \mathrm{~b}} \quad$ or $\quad$ 2-dicyanomethylenethiazole ${ }^{10 \mathrm{c}}$ respectively as acceptor end show a BLA value close to zero. This indicates that 
incorporation of acceptor $\mathbf{P h F u}$ leads to moderately-polarized structures, and this fact may have a positive effect on the NLO behavior (see NLO section) as it places compounds Py0PhFu-Py1PhFu, at least in the solid state, far from the cyanine limit. In this context, structure of Py1PhFu is similar to that of its recently reported 2dicyanomethylenethiophene ${ }^{23}$ analogue.

The structural parameters for $\mathbf{P y} \mathbf{1} \mathbf{M e} \mathbf{e}_{2} \mathbf{F u}$ (Figure 3) indicate a limited polarization of the donor unit given that the $\delta \mathrm{r}$ parameter and the $\mathrm{C}_{4}-\mathrm{C}_{\mathrm{exo}}$ bond length $(\mathrm{C} 3=\mathrm{C} 14$ bond in Py1Me $\mathbf{M}_{2} \mathbf{F}$, see Figure 2) both exhibit values corresponding to a fully quinoid $4 H$ pyranylidene ring. In fact, $1.354 \AA$ is even shorter than the $C_{4}-C_{\text {exo }}$ bond in 2,2',6,6'tetraphenylbipyranylidene (1.385 $\AA$ ) taken as reference for a quinoidal derivative. ${ }^{24}$ On the other hand, BLA value for $\mathbf{P y} \mathbf{1 M e} \mathbf{M e}_{2} \mathbf{F u}$ is $0.056 \AA$ (Figure 3), which locates the chromophore in the region where $\beta$ is maximized due to an optimal degree of mixing between neutral and charge-separated canonical forms. ${ }^{25}$

Moreover, comparison of the structural parameters of $\mathbf{P y 1 P h F u} / \mathbf{P y} 1 \mathbf{M e} \mathbf{F}_{2} \mathbf{F u}$, with a proaromatic/non proaromatic furanone as acceptor fragment respectively indicates that $\mathbf{P y}_{\mathbf{1 M e}} \mathbf{F u}$ presents a more alternated structure.

Concerning series Bz, single crystals of derivative Bz0PhFu were obtained by slow diffusion of propan-2-ol into a solution of the chromophore in $\mathrm{CH}_{2} \mathrm{Cl}_{2}$ at room temperature. Compound Bz0PhFu crystallizes in the monoclinic space group P21/c, and some of the main features of this structure are similar to those of the described above. For this compound, another X-ray structure has been previously reported, different from the structure submitted here: it claims a P-1 space group, incorporating a $\mathrm{CHCl}_{3}$ crystallized molecule. ${ }^{26}$ Both structures have the same geometric configurations. 
In our structure, BLA value is $-0.005 \AA$, indicating that this chromophore is close to the cyanine limit in the solid state, and therefore located in region C of Marder's plot. ${ }^{3 \mathrm{~b}}$ This $^{\text {s. }}$ data also accounts for a more polarized structure than its analogue Py0PhFu (BLA = 0.023, Figure 3) pointing out to a better electron-donating ability of the benzothiazole moiety compared to that of the pyranylidene ring. This behavior is in agreement with the trend followed by octupolar merocyanine dyes designed for two-photon absorption (TPA) with these donors. ${ }^{27}$

A complete description of the crystal structure is reported in the Supporting Information (SI), section 5 .

CCDC-1407292 (Bz0PhFu), CCDC-1407293 (Py0PhFu), CCDC-1407294 (Py1Me2Fu) and CCDC-1407295 (Py1PhFu) contain the supplementary crystallographic data for this paper. These data can be obtained free of charge from The Cambridge Crystallographic Data Centre.

${ }^{\mathbf{1}} \mathbf{H}$ NMR Studies. ${ }^{1} \mathrm{H}$ NMR spectroscopy affords valuable information about both the geometry and the ground electronic state polarization of the chromophores herein studied. Concerning their stereochemistry, analysis of ${ }^{3} J_{\mathrm{HH}}$ coupling constants indicates an all-trans geometry along the spacer, with ${ }^{3} J_{\mathrm{HH}}$ values ranging from 14.9 to $13.4 \mathrm{~Hz}$ for the $\mathrm{CH}=\mathrm{CH}-$ bonds and from 13.1 to $11.6 \mathrm{~Hz}$ for the $=\mathrm{CH}-\mathrm{CH}=$ bonds. This stereochemistry mimics those observed by X-ray diffraction for compounds Py0PhFu, Py1PhFu, Py1Me $e_{2}$, Bz0PhFu.

Regarding the ground electronic state polarization of the studied compounds, the analysis of $\Delta J$ values (defined as the difference between the averaged ${ }^{3} J_{\mathrm{HH}}$ values of the double and single bonds along the polymethine chain $)^{28}$ for $\mathbf{P y} \mathbf{1}\left(\mathbf{P h F u}, \mathbf{M e} \mathbf{e}_{2} \mathbf{F u}, \mathbf{B u F u}\right)$, obtained from spectra registered in $\mathrm{CDCl}_{3}(1.0 \mathrm{~Hz}, 2.3 \mathrm{~Hz}$ and $1.5 \mathrm{~Hz}$ respectively), indicates that 
polarization increases in the order $\mathbf{P y} 1 \mathbf{M e}_{2} \mathbf{F u}<\mathbf{P y 1 B u F u}<\mathbf{P y 1 P h F u}$, which reveals the fact that quinoidal butenolides (PhFu, BuFu) are better electron-withdrawing groups than nonquinoidal $\mathbf{M e}_{2} \mathbf{F u}$. For PhFu (with a phenyl group) and BuFu (with the tert-butyl substituent), the former presents a higher electron-withdrawing character.

For the analysis of the benzothiazolylidene derivatives, see SI, section 3, Figure S25.

Finally, for all chromophores, the chemical shifts of the $\mathrm{H}$ atoms along the spacer show the typical oscillatory behavior ${ }^{29}$ that reflects the alternation in the electron density of the carbon atoms to which $\mathrm{H}^{`} \mathrm{~s}$ are bonded: e.g, for Py1BuFu, starting from pyranylidene donor group, in $\mathrm{CDCl}_{3}$ 5.68, 7.08, 6.59, 6.73 ppm.

Calculated Structures. The molecular geometries of all chromophores were optimized at the CPCM-M06-2X/6-31G* level in dichloromethane, starting from configurations depicted in Scheme 3 which are supported by crystallographic and spectral data. The resulting theoretical structures were nearly planar.

Analysis of natural bond orbital (NBO) atomic charge on various molecular domains (Table 1) allows a deeper understanding of the polarization of the molecules.

TABLE 1. Calculated NBO charges on various molecular domains from the optimized CPCM-M06-2X/6-31G* molecular geometries (in $\mathrm{CH}_{2} \mathrm{Cl}_{2}$ ).

\begin{tabular}{lccc}
\hline Compd & Donor & $\pi$-spacer & Acceptor \\
\hline Py0PhFu & +0.371 & +0.005 & -0.376 \\
Py0Me 2 Fu & +0.340 & -0.054 & -0.286 \\
Py0BuFu & +0.340 & -0.007 & -0.333 \\
Py1PhFu & +0.324 & +0.027 & -0.351 \\
Py1Me 2 Fu $_{\text {Py1BuFu }}$ & +0.297 & -0.034 & -0.263 \\
Bz0PhFu $_{\text {Bz0Me }}$ Fu & +0.297 & +0.008 & -0.305 \\
\hline & +0.465 & -0.059 & -0.406 \\
& & -0.131 & -0.301
\end{tabular}




\begin{tabular}{llll} 
Bz0BuFu & +0.436 & -0.072 & -0.364 \\
Bz1PhFu & +0.421 & -0.043 & -0.378 \\
Bz1Me2Fu & +0.394 & -0.114 & -0.280 \\
Bz1BuFu & +0.397 & -0.067 & -0.330 \\
\hline
\end{tabular}

In general, the positive charge is concentrated on the donor ring and the negative charge on the acceptor moiety, although in the $\mathbf{B z}$ series, the $\pi$-spacer supports a slight negative charge, more important for derivatives $\mathbf{M e}_{2} \mathbf{F u}$.

For both series (Py and $\mathbf{B z}$ ) comparison of compounds that only differ in the acceptor group shows that polarization of the chromophores increases in the order $\mathbf{M e}_{2} \mathbf{F u}<\mathbf{B u F u}<\mathbf{P h F u}$, in agreement with ${ }^{1} \mathrm{H}$ NMR data and X-ray studies $(\mathbf{P y} 1 \mathrm{PhFu} /$ $\mathbf{P y}_{1} \mathbf{M e}_{2} \mathbf{F u}$ ), thus confirming the higher electron-withdrawing ability for butenolide $\mathbf{P h F u}$.

For a given D/A pair, lengthening the conjugated spacer with a vinylene unit leads to a decrease in the charge of the end groups and, in consequence, to more alternated structures, in line with the findings from the X-ray analysis (Py0PhFu/Py1PhFu).

Finally, comparison of the charges between analogous chromophores of the $\mathbf{P y}$ and $\mathbf{B z}$ series shows that the latter are more polarized than their $\mathbf{P y}$ analogues, indicating a major contribution of the zwitterionic form to the ground state, as it has been shown by the crystallographic study of Py0PhFu/Bz0PhFu.

Electrochemistry. The redox properties of target chromophores together with acceptors PhFu, $\mathrm{Me}_{2} \mathbf{F u}, \mathbf{B u F u}$ were studied by cyclic voltammetry (CV) in $\mathrm{CH}_{2} \mathrm{Cl}_{2}$ and the results are gathered in Table 2 . 
TABLE 2. Electrochemical data $^{a}$ and $E_{\text {HOMO }}$ and $E_{\text {LUMO }}$ values theoretically calculated. $^{b}$

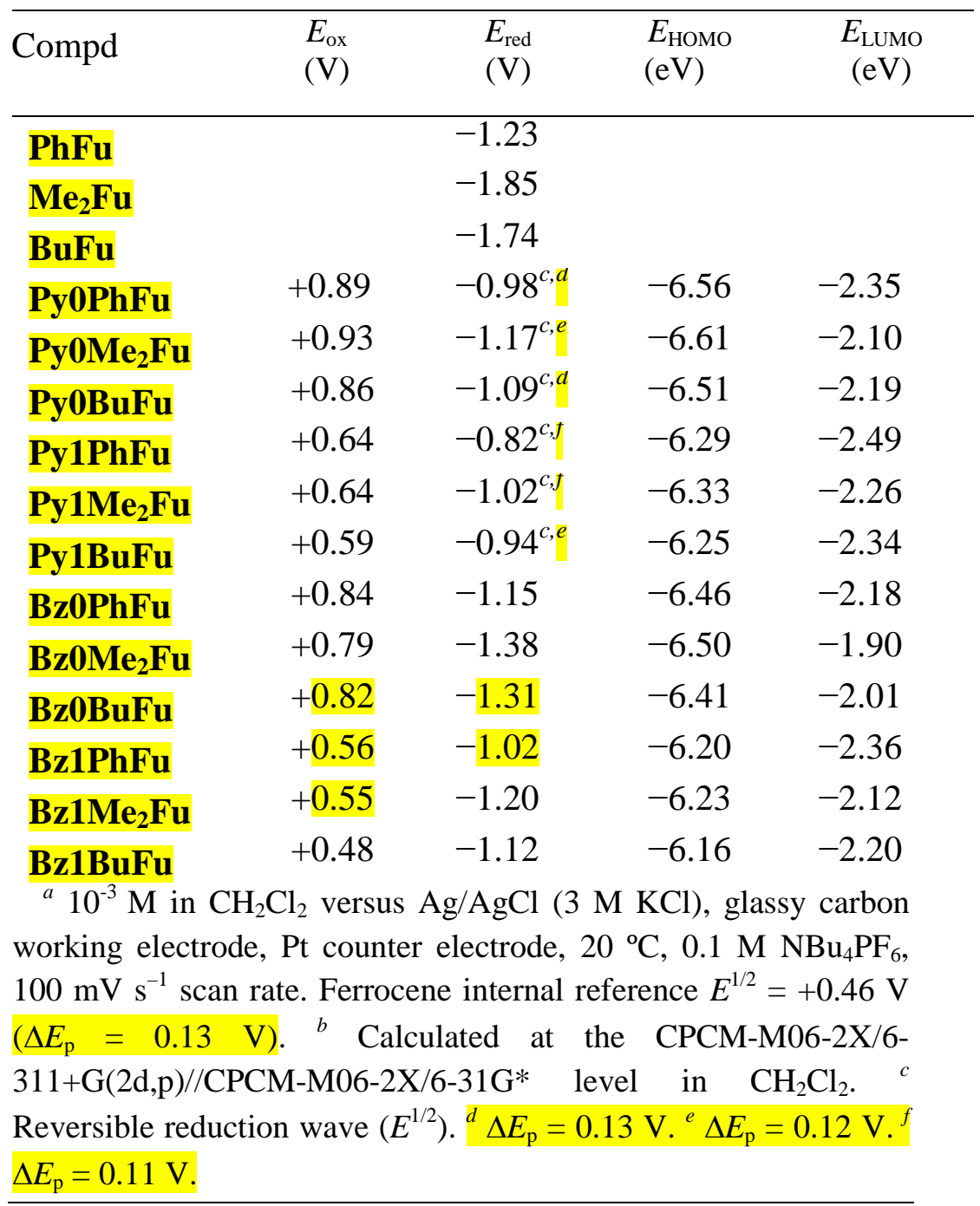

Voltammograms for acceptors $\mathbf{P h F u , M e} \mathbf{M} \mathbf{F u}, \mathbf{B u F u}$ show an irreversible reduction wave. Values of $E_{\text {red }}$ depend on the type of the furanone. Thus, the non-proaromatic acceptor $\mathbf{M e}_{2} \mathbf{F u}$ presents the highest $\left|E_{\text {red }}\right|$ data. For proaromatic acceptors $\mathbf{P h F u , B u F u}$, the presence of a tert-butyl group in C4 implies a lower electron-withdrawing ability with higher $\left|E_{\text {red }}\right|$ for BuFu compared to $\mathbf{P h F u}$. 
All D- $\pi$-A systems show one oxidation and one reduction waves corresponding to the donor moiety and the acceptor unit, respectively. Reduction process for the series Py is reversible. When $E_{\text {red }}$ data are compared in both $\mathbf{P y}$ and $\mathbf{B z}$ series, results follow the same trend encountered for the isolated acceptors, i.e. the reduction process is easier in the order: systems $\mathbf{M e}_{2} \mathbf{F u}<$ systems $\mathbf{B u F u}<$ systems $\mathbf{P h F u}$, thus confirming the superior electronwithdrawing effect of acceptor $\mathbf{P h F u}$, in agreement with ${ }^{1} \mathrm{H}$ NMR study, crystal structures $(\mathbf{P y 1 P h F u} / \mathbf{P y 1 M e} \mathbf{F u})$ and theoretical data. Inspection of calculated $E_{\mathrm{LUMO}}$ data indicates that derivatives of acceptor $\mathbf{P h F u}$ have the lowest values. On the other hand, $E_{\text {ox }}$ values are also influenced by the acceptor fragment, being compounds derived from BuFu (except Bz0BuFu) the most easily oxidized. $E_{\text {HOMO }}$ data are in agreement with this observed trend.

Moreover, for a given acceptor, it can be seen that both oxidation and reduction processes become easier on chain lengthening (for example cf. Py0PhFu/Py1PhFu; Bz0PhFu/Bz1PhFu), pointing out to a weaker interaction between the donor and acceptor ends. In line with this analysis, compounds $\mathbf{0}$ show higher calculated gaps than their vinylogues 1 .

Comparison of compounds $\mathbf{P y}$ with their analogues of series $\mathbf{B z}$ shows lower (higher) oxidation (reduction) potentials for the latter, pointing out to the higher electron-donating ability of the benzothiazole moiety. This result is in agreement with the literature data. ${ }^{30}$ Furthermore, the observed trends in $E_{\mathrm{ox}}$ and $E_{\text {red }}$ are also confirmed by theoretical calculations, which show that both $E_{\text {HOMO }}$ and $E_{\text {LUMO }}$ values increase on passing from pyran derivatives Py to their benzothiazole Bz counterparts.

\section{Vibrational spectroscopy.}

Infrared (IR) spectroscopy can afford useful information about the degree of ground state polarization of the merocyanines herein studied. ${ }^{10,23,31}$ Thus, the stretching vibration 
frequencies of the $\mathrm{C} \equiv \mathrm{N}$ and $\mathrm{C}=\mathrm{O}$ bonds are sensitive to the increasing electron density on them, downshifting upon ground state polarization. Indeed, taking the isolated acceptors PhFu, $\mathrm{Me}_{2} \mathrm{Fu}, \mathrm{BuFu}$ as references (Table 3), the $v(\mathrm{C} \equiv \mathrm{N})$ and $v(\mathrm{C}=\mathrm{O})$ frequency values of

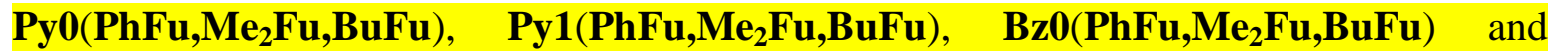
$\operatorname{Bz1}\left(\mathbf{P h F u}, \mathrm{Me}_{2} \mathbf{F u}, \mathbf{B u F u}\right.$ appear at significantly lower frequencies, affirming the polarization from the donor to the butenolide group.

TABLE 3. Infrared data (measured on nujol suspension; data in $\mathrm{cm}^{-1}$ ).

\begin{tabular}{|c|c|c|c|c|c|}
\hline Compd & $(\mathrm{C} \equiv \mathrm{N})$ & $(\stackrel{\nu}{\mathrm{C}}=\mathrm{O})$ & Compd & $\left.{ }^{\prime} \mathrm{C} \equiv \mathrm{N}\right)$ & $v(\mathrm{C}=\mathrm{O})$ \\
\hline PhFu & 2231 & 1752 & & & \\
\hline $\mathrm{Me}_{2} \mathrm{Fu}$ & 2239 & 1769 & & & \\
\hline BuFu & 2238 & 1776 & & & \\
\hline Py0PhFu & 2213 & 1739 & Bz0PhFu & 2207 & 1722 \\
\hline $\mathrm{PyOMe}_{2} \mathrm{Fu}$ & 2206 & 1738 & $\mathrm{BzOMe}_{2} \mathrm{Fu}$ & 2210 & 1723 \\
\hline Py0BuFu & 2215 & 1746 & Bz0BuFu & 2209 & 1720 \\
\hline Py1PhFu & 2217 & 1742 & Bz1PhFu & 2200 & 1729 \\
\hline $\mathrm{Py}_{1 M e_{2}} \mathrm{Fu}$ & 2201 & 1742 & $\mathrm{Bz} \mathrm{Me}_{2} \mathrm{Fu}$ & 2213 & 1739 \\
\hline Py1BuFu & 2219 & 1749 & Bz1BuFu & 2191 & 1702 \\
\hline
\end{tabular}

Table 3 reveals two different trends concerning the dependence of $v(\mathrm{C} \equiv \mathrm{N})$ on chain lengthening. Thus, for pyranylidene-containing chromophores (Py series), increasing the length of the polyenic spacer gives rise to a frequency upshift of $v(\mathrm{C} \equiv \mathrm{N})$ (also for $v(\mathrm{C}=\mathrm{O})$ values), except for Py0Me ${ }_{2} \mathbf{F u}$ and $\mathbf{P y} \mathbf{1 M e} \mathbf{F}_{2} \mathbf{F u}(v(\mathrm{C} \equiv \mathrm{N}))$. This reveals a decreased polarization (and zwitterionic character) for the longer derivatives $\mathbf{1}$, in agreement with calculated data and X-ray (Py0PhFu/Py1PhFu). 
On the other hand, lengthening the spacer in the series $\mathbf{B z}$ leads to a frequency downshift of the $v(\mathrm{C} \equiv \mathrm{N})$ vibration (compounds $\mathbf{B z 0 M e} \mathbf{F}_{2} \mathbf{F u}-\mathbf{B z}_{\mathbf{M}} \mathbf{M e}_{2} \mathbf{F u}$ have similar values), which suggests a higher zwitterionic character for the longer derivatives. This behavior may be related to the more extended conjugation path, which facilitates polarization of the $\pi$ system towards the butenolide end and, although this trend is uncommon, some examples are reported. ${ }^{10 c, 11 e, 32}$

The lower frequencies of both $v(\mathrm{C} \equiv \mathrm{N})$ and $v(\mathrm{C}=\mathrm{O})$ bands in series $\mathrm{Bz}$ compared to those of series $\mathbf{P y}$ (derivatives of furanone $\mathbf{M e}_{2} \mathbf{F u}$ do not fulfill this trend for the $\mathrm{C} \equiv \mathrm{N}$ bond, see below discussion about Raman spectroscopy) show the stronger electrondonating ability of the benzothiazole group in relation to the pyranylidene one, as disclosed by computational studies and X-ray (Py0PhFu/ Bz0PhFu).

Figure 4 shows the Raman spectra of the studied compounds. The $v(\mathrm{C} \equiv \mathrm{N})$ in compound Py0PhFu appears at $2214 \mathrm{~cm}^{-1}$ and shifts to $2210 \mathrm{~cm}^{-1}$ in $\mathbf{B z 0 P h F u}$, reaffirming the greater electron donor ability of the latter. The corresponding $v(\mathrm{C}=\mathrm{O})$ appears at $1736 \mathrm{~cm}^{-1}$ in Py0PhFu and $1708 \mathrm{~cm}^{-1}$ in BzOPhFu. This frequency downshift on BzOPhFu is related with a larger contribution of the enolic structure C upon charge polarization, (Scheme 7) which is consistent with the five member ring viewed as an aromatic furan and substituted at the $\beta$ position ( $\alpha$ in the furanone ring) by the cyano group. This aromaticity gain upon polarization favors a greater delocalization of the charge on the carbonyl group. In this regard, the cyano is placed in a cross conjugated fashion constraining its electronwithdrawal character. 

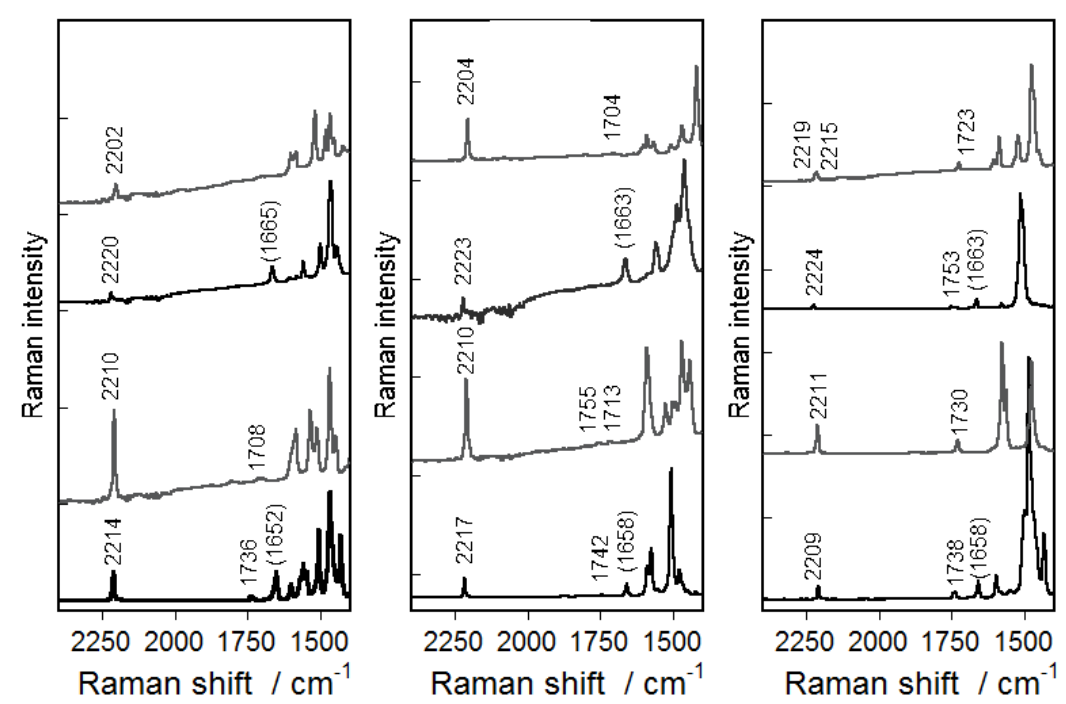

Figure 4. 1064 nm FT-Raman spectra in solid state of the studied compounds. From the bottom to the top: Left: Py0PhFu, Bz0PhFu, Py1PhFu and Bz1PhFu. Middle: Py0BuFu, Bz0BuFu, Py1BuFu and Bz1BuFu. Right: Py0Me Fu, Bz0Me Fu, Py1Me Fu and $\mathrm{Bz1Me}_{2} \mathrm{Fu}$.

Scheme 7. Canonical forms upon charge polarization for chromophore Bz0PhFu.<smiles>CCc1ccccc1S/C=C1\OC(=O)C(C#N)=C1/C=C1\OC(=O)C(C#N)=C1/C=C/c1nc2ccccc2s1</smiles>

A<smiles></smiles>

D
B<smiles></smiles> 
On increasing the length of the $\mathrm{C}=\mathrm{C} / \mathrm{C}-\mathrm{C}$ spacer from Bz0PhFu to Bz1PhFu the $v(\mathrm{C} \equiv \mathrm{N})$ band shifts as $2210 \mathrm{~cm}^{-1} \rightarrow 2202 \mathrm{~cm}^{-1}$, whereas $v(\mathrm{C}=\mathrm{O})$ Raman band is not detected, likely due to the strong enolic character that dramatically decreases its Raman intensity, as it is typical of alcoholate compounds. This situation is in agreement with an important increase of the contribution of the C type canonical form (Scheme 7) for compound Bz1PhFu further indicating that, by lengthening the $\pi$-spacer in series $\mathbf{B z}$ a more polarized structure results. In contrast, in Py series, given their weaker electrondonating character, a frequency upshift behavior is observed. Moreover, the bands at 1652 (Py0PhFu) and 1665 (Py1PhFu) $\mathrm{cm}^{-1}$ are due to the $v(\mathrm{C}=\mathrm{C})$ modes in the pyranylidene moieties.

The replacement of the phenyl group in $\beta$ position of the furanone by a tert-butyl one does not change the main tendencies (downshifts of the $v(\mathrm{C} \equiv \mathrm{N})$ and $v(\mathrm{C}=\mathrm{O})$ Raman frequencies, on passing from Py0BuFu to Bz0BuFu and from Bz0BuFu to Bz1BuFu) observed for the phenyl substituted series. For derivatives $\mathbf{0}$, different trends depending on the donor are observed: for pyranylidene derivatives, frequencies upshift from Py0PhFu to Py0BuFu, due to the strong steric crowding that the tert-butyl group exerts on the vinylene bridge, that weakens the donor-acceptor coupling (Figure 5).

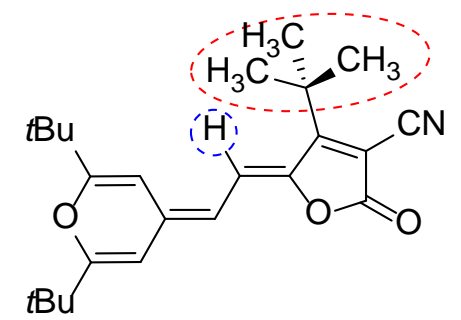

Figure 5. Crowding effect of the tert-butyl group that decreases the molecular polarization (chromophore Py0BuFu). 
On the other hand, for benzothiazolylidene systems Bz0PhFu and Bz0BuFu, the frequencies scarcely change.

For chromophores bearing butenolide $\mathbf{M e}_{2} \mathbf{F u}$, a canonical form similar to $\mathrm{C}$ in Scheme 7 does not longer exist, and the acceptor part of the molecule can be viewed as an acceptor with a cyano and an ester groups, placed one after the other, in a cross-conjugated fashion, and therefore competing for the negative charge. Given the disposition of the two groups, the cyano, with a slightly stronger electron-withdrawing character than the ester, should have a preferential situation to drain charge from the bridge. This can be the reason for the lower frequency for the $v(\mathrm{C} \equiv \mathrm{N})$ band in $\mathbf{P y 0} \mathbf{M e} \mathbf{M}_{2} \mathbf{F u}\left(2209 \mathrm{~cm}^{-1}\right)$ compared to Py0PhFu $\left(2214 \mathrm{~cm}^{-1}\right)$. On the other hand, the $v(\mathrm{C}=\mathrm{O})$ frequencies scarcely change due to the lack of enolic character (form C in Scheme 7), which is compensated by the inductive effect of the oxygen in the ester. These two trends are also observed in the IR data (Table 3).

For derivative $\mathbf{B z 0 M e} \mathbf{F u}_{2} \mathbf{F u}$, the $v(\mathrm{C}=\mathrm{O})$ bands undergo significant upshifts regarding Bz0PhFu or Bz0BuFu, which further reaffirm the isolation of the carbonyl groups in a position unaffected by the charge polarization (fully gathered by the nitriles).

Overall, the replacement of $\mathbf{P h F u}, \mathbf{B u F u}$ units as acceptors by furanone $\mathbf{M e} \mathbf{e}_{2} \mathbf{F u}$ involves a decrease in the polarization of the final chromophores.

A study of the frequency behavior of the $v(\mathrm{C} \equiv \mathrm{N})$ and $v(\mathrm{C}=\mathrm{O})$ bands in the oxidized and reduced forms according to the redox processes in the $\mathrm{CV}$ is also carried out and presented in the SI file, section 6. 
UV-Vis Spectroscopy. The UV-vis absorption data of push-pull systems in solvents with different polarity are collected in Table 4. All chromophores show very strong and broad electronic absorption bands within the visible region, with structured bands in some of the solvents studied. (See spectra in the SI).

Electron densities related to frontier orbitals (see topologies for Py1BuFu chosen as the model compound in Figure 6 and for the rest of the chromophores in SI) are mainly supported by the donor unit and its nearest polyenic fragment for the HOMO, and by the butenolide ring in the case of LUMO.

Figure 6. Illustration of the HOMO (bottom) and LUMO (top) of compound Py1BuFu.
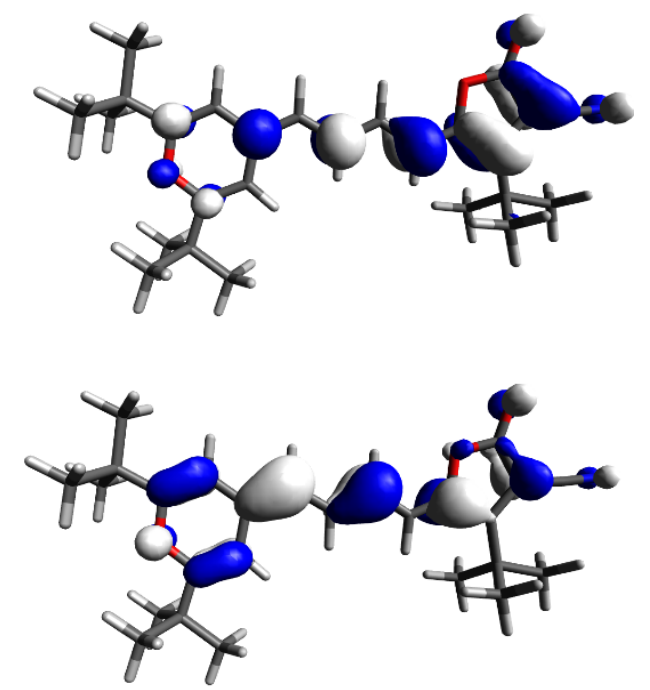

TD-DFT calculations (CPCM-M06-2X/6-311+G(2d,p)//CPCM-M06-2X/6-31G* level in $\mathrm{CH}_{2} \mathrm{Cl}_{2}$ ) describe the first excited state as a consequence of a one-electron transition from the HOMO to the LUMO. The large HOMO-LUMO overlap is responsible for the strength of the absorption bands. 
TABLE 4. UV-Vis data ${ }^{a}$

\begin{tabular}{|c|c|c|c|}
\hline Compd & $\begin{array}{l}\lambda_{\max }(\log \varepsilon) \\
1,4 \text {-dioxane }\end{array}$ & $\lambda_{\max }(\log \varepsilon)$ & $\lambda_{\text {max }}(\log \varepsilon)$ \\
\hline Py0PhFu & $\begin{array}{l}503 \text { (sh) } \\
536(4.71) \\
568 \text { (sh) }\end{array}$ & $\begin{array}{l}519 \text { (sh) } \\
559(4.79) \\
591(4.81)\end{array}$ & $\begin{array}{l}518 \text { (sh) } \\
558(4.79) \\
597(4.85)\end{array}$ \\
\hline $\mathrm{PyOMe}_{2} \mathrm{Fu}$ & $\begin{array}{l}491(4.56) \\
515(4.57) \\
553 \text { (sh) }\end{array}$ & $\begin{array}{l}499 \text { (sh) } \\
532(4.69) \\
568(4.57)\end{array}$ & $\begin{array}{l}498 \text { (sh) } \\
529(4.70) \\
563 \text { (sh) }\end{array}$ \\
\hline Py0BuFu & $\begin{array}{l}487 \text { (sh) } \\
513(4.68) \\
554 \text { (sh) }\end{array}$ & $\begin{array}{l}505 \text { (sh) } \\
539 \text { (4.79) } \\
573 \text { (sh) }\end{array}$ & $\begin{array}{l}506 \text { (sh) } \\
544(4.75) \\
580 \text { (sh) }\end{array}$ \\
\hline Py1PhFu & $589(4.63)$ & $\begin{array}{l}585 \text { (sh) } \\
635 \text { (4.73) } \\
684 \text { (sh) }\end{array}$ & $\begin{array}{l}589(\mathrm{sh}) \\
638(4.71) \\
692(4.63)\end{array}$ \\
\hline $\mathrm{Py}_{1 M e_{2}} \mathrm{Fu}$ & $538(4.63)$ & $\begin{array}{l}585 \text { (4.70) } \\
644 \text { (sh) }\end{array}$ & 575 (4.69) \\
\hline Py1BuFu & $551(4.47)$ & $599(4.50)$ & $\begin{array}{l}598 \text { (4.47) } \\
679 \text { (sh) }\end{array}$ \\
\hline Bz0PhFu & $\begin{array}{l}529(\mathrm{sh}) \\
566(4.80)\end{array}$ & $\begin{array}{l}538 \text { (sh) } \\
576(5.10)\end{array}$ & $\begin{array}{l}538 \text { (sh) } \\
579(5.10)\end{array}$ \\
\hline $\mathrm{BzOMe}_{2} \mathrm{Fu}$ & $\begin{array}{l}521(4.74) \\
541(4.78)\end{array}$ & $\begin{array}{l}523(\mathrm{sh}) \\
553(4.93)\end{array}$ & $\begin{array}{l}524(\mathrm{sh}) \\
559(4.97)\end{array}$ \\
\hline Bz0BuFu & $\begin{array}{l}521(\mathrm{sh}) \\
550(4.85)\end{array}$ & $\begin{array}{l}529(4.75) \\
564(5.10)\end{array}$ & $\begin{array}{l}533(4.72) \\
567(5.67)\end{array}$ \\
\hline Bz1PhFu & $\begin{array}{l}611 \text { (sh) } \\
642(4.59)\end{array}$ & $\begin{array}{l}628(\mathrm{sh}) \\
678(5.00)\end{array}$ & $\begin{array}{l}634(\mathrm{sh}) \\
687(5.23)\end{array}$ \\
\hline $\mathrm{Bz} \mathrm{Me}_{2} \mathrm{Fu}$ & $585(4.46)$ & $\begin{array}{l}596(\mathrm{sh}) \\
634(4.78)\end{array}$ & $\begin{array}{l}596(\mathrm{sh}) \\
644(4.84)\end{array}$ \\
\hline Bz1BuFu & $594(4.67)$ & $\begin{array}{l}618(4.86) \\
656(5.00)\end{array}$ & $\begin{array}{l}623(\mathrm{sh}) \\
669(5.12)\end{array}$ \\
\hline
\end{tabular}

${ }^{a}$ All $\lambda_{\max }$ data in $\mathrm{nm}$.

Comparison of series $\mathbf{0}$ and $\mathbf{1}$ indicates that the $\lambda_{\max }$ values increase on lengthening the spacer, effect that is more accentuated in $\mathrm{CH}_{2} \mathrm{Cl}_{2}$ or DMF than in the less polar 1,4dioxane. Taking as model pairs Py0PhFu/Py1PhFu and Bz0PhFu/Bz1PhFu, this 
augmentation reaches $\sim 100 \mathrm{~nm},{ }^{33}$ pointing to weakly alternated structures, more polarized in the case of $\mathbf{B z}$ derivatives (102 nm, $0.32 \mathrm{eV}$ in $\mathrm{CH}_{2} \mathrm{Cl}_{2} ; 108 \mathrm{~nm}, 0.34 \mathrm{eV}$ in DMF) than in Py systems (0.29 eV both in $\mathrm{CH}_{2} \mathrm{Cl}_{2}$ and $\mathrm{DMF}$ ). This trend is in agreement with other experimental techniques (IR, Raman, CV, Py0PhFu/Bz0PhFu X-ray) and calculated NBO charges.

When different furanones are compared, $\lambda_{\max }$ decreases in the following order $\mathbf{P h F u}>\mathbf{B u F u}>\mathbf{M e}_{2} \mathbf{F u}$. This behavior can be explained, on the one hand, by the character (quinoid or non-quinoid) of the acceptor moiety. Thus, the presence of the quinoid ring causes a red shift of the maximum absorption wavelength in derivatives PhFu, BuFu when compared to their analogues $\mathbf{M e} \mathbf{F u}$ (e.g., $23 \mathrm{~nm}(0.08 \mathrm{eV})$ for $\mathbf{P y 0 P h F u} / \mathbf{P y 0 M e} \mathbf{F u}$ and 5 nm $(0.02 \mathrm{eV})$ for $\mathbf{P y 0 B u F u} / \mathbf{P y 0} \mathbf{M e} \mathbf{F}_{2} \mathbf{F u}$, both in $\left.\mathrm{CH}_{2} \mathrm{Cl}_{2}\right)$. On the other hand, the replacement of the phenyl ring in compounds $\mathbf{P h F u}$ for a tert-butyl group in derivatives BuFu gives rise to a hypsochromic shift (e.g., $85 \mathrm{~nm}(0.26 \mathrm{eV})$ for Py1PhFu/Py1BuFu and $22 \mathrm{~nm}(0.06 \mathrm{eV})$ for Bz1PhFu/Bz1BuFu, both in $\left.\mathrm{CH}_{2} \mathrm{Cl}_{2}\right)$. The same effect was observed for cyanine dyes bearing a $4 H$-pyran-4-ylidene moiety. ${ }^{34}$ The order above mentioned suggests a parallel decrease in the corresponding acceptor strengths (PhFu $>$ BuFu $>$ Me $\mathbf{F u}$ ), in line with the results of ${ }^{1} \mathrm{H}$ NMR spectroscopy, theoretical data and $\mathrm{CV}$.

In general, derivatives of $\mathbf{B z}$ series present $\lambda_{\max }$ values lower than their $\mathbf{P y}$ analogues, ${ }^{27}$ although for systems $\mathbf{1}$ this trend is not observed for all the solvents studied. Moreover, $\mathbf{B z}$ systems show larger $\varepsilon$ values than their Py equivalents, and for some solvents, values beyond $10^{5}$ were found, in agreement with other benzothiazolylidene- $\pi$-A chromophores previously reported. ${ }^{11 c, 11 e, 27,35}$ 
Concerning the dependence of the band position on solvent polarity, positive solvatochromism in low polarity solvents ( $c$. dioxane and $\mathrm{CH}_{2} \mathrm{Cl}_{2}$ ) is observed for all chromophores. On the other hand, when data in $\mathrm{CH}_{2} \mathrm{Cl}_{2}$ and $\mathrm{DMF}$ are compared, the bathochromic shift encountered becomes smaller for derivatives $\mathbf{P h F u / B u F u , ~ w h e r e a s ~ f o r ~}$ compounds $\mathbf{M e}_{2} \mathbf{F u}$, solvatochromism found depends on the donor unit: slightly negative for $\mathbf{P y}$ derivatives ${ }^{36}$ and positive for $\mathbf{B z}$ systems.

Nonlinear Optical properties. The second-order nonlinear optical properties of chromophores herein studied were measured by electric field-induced second harmonic generation (EFISHG) in dichloromethane at $1907 \mathrm{~nm}$, and the zero-frequency $\mu \beta_{0}$ values were calculated by using the two-level model. ${ }^{37}$ In the case of the benzothiazolylidene systems (series $\mathbf{B z}$ ), the lowest energy absorption band, which is the more intense one for each compound, has been used. Given that for derivatives of Py series the lowest energy bands in some of the spectra became weak shoulders (indistinguishable in some of the longest compounds), in order to compare $\mu \beta_{0}$ values in this series, the high intensity central band has been considered (Table 5). For the sake of comparison, Disperse Red 1, a common benchmark for organic NLO chromophores shows a $\mu \beta_{0}$ value of ca. $490 \times 10^{-48}$ esu and $425 \times 10^{-48}$ in $\mathrm{CH}_{2} \mathrm{Cl}_{2}$ and $\mathrm{DMF}$ respectively, under the same experimental conditions.

TABLE 5. Experimental and calculated NLO Properties

\begin{tabular}{lccc}
\hline Compd & $\begin{array}{c}\mu \beta^{a} \\
\left(10^{-48} \text { esu }\right)\end{array}$ & $\begin{array}{c}\mu \beta_{0}{ }^{b} \\
\left(10^{-48} \text { esu }\right)\end{array}$ & $\begin{array}{c}\mu \beta^{c} \\
\left(10^{-48} \text { esu }\right)\end{array}$ \\
\hline Py0PhFu & 950 & 575 & 521 \\
Py0Me 2 Fu & 800 & 510 & 395 \\
Py0BuFu & 850 & 530 & 499
\end{tabular}




\begin{tabular}{|c|c|c|c|}
\hline Py1PhFu & 2850 & 1420 & 2125 \\
\hline $\mathrm{Py}_{1 M \mathrm{M}_{2} \mathrm{Fu}}$ & 2100 & 1190 & 1798 \\
\hline Py1BuFu & 1800 & 990 & 1801 \\
\hline Bz0PhFu & 560 & 325 & 580 \\
\hline $\mathrm{BzOMe}_{2} \mathrm{Fu}$ & 520 & 320 & 477 \\
\hline Bz0BuFu & $d$ & - & 531 \\
\hline Bz1PhFu & 3300 & 1440 & 2136 \\
\hline $\mathrm{Bz}_{\mathrm{MMe}} \mathrm{Fu}$ & 2900 & 1430 & 1838 \\
\hline Bz1BuFu & 2600 & 1210 & 1797 \\
\hline $\begin{array}{l}{ }^{a} \mu \beta \text { values } \\
\text { xperimental u } \\
\text { zOPhFu-Bzol } \\
\text { lues in } \mathrm{CH}_{2} \\
\text { odel. }{ }^{c} \text { Calcul } \\
/ 6-31 \mathrm{G}^{*} \text { leve } \\
\text { liable value } \\
\text { stability in } \\
\text { easurements. }\end{array}$ & $\begin{array}{l}\text { nined } \\
\text { inty les } \\
\text { ( 20\% } \\
\text { alculate } \\
t \text { the } \mathrm{H} \\
\mathrm{H}_{2} \mathrm{Cl}_{2} . \\
\text { ot be } \\
\mathrm{Cl}_{2}\end{array}$ & $\begin{array}{l}\mathrm{I}_{2} \mathrm{Cl}_{2} \text { a } \\
\pm 15 \% \\
\text { Experi } \\
\text { ng the } \\
\mathrm{G}^{*} / / \mathrm{C} \\
\text { this c } \\
\text { ided c } \\
\text { the }\end{array}$ & $\begin{array}{l}07 \mathrm{~nm} \\
\text { ept for } \\
\text { tal } \mu \beta_{0} \\
\text { o-level } \\
\text { 1-M06- } \\
\text { ound a } \\
\text { to its } \\
\text { ne of }\end{array}$ \\
\hline
\end{tabular}

As it has been already observed for other NLO-chromophores previously studied, lengthening the polyenic chain by a single vinylene unit gives rise to an important increase in the NLO response, which is remarkably pronounced for series Bz: $\mu \beta_{0}(\mathbf{B z 1 P h F u}) / \mu \beta_{0}(\mathbf{B z 0 P h F u})=4.4$ and $\mu \beta_{0}(\mathbf{B z 1 M e} \mathbf{F u}) / \mu \beta_{0}(\mathbf{B z 0 M e} \mathbf{F u})=4.5$.

Regarding the influence of acceptor structure on the NLO properties of the studied chromophores, derivatives of the proaromatic butenolide nitrile PhFu have the best NLO responses (for $\mathbf{B z O P h F u}-\mathbf{B z 0 M e} \mathbf{F u}$ almost the same value was obtained).

Comparison of analogous compounds in $\mathbf{P y}$ and $\mathbf{B z}$ series reveals that, for derivatives $\mathbf{0}$, pyranylidene-containing chromophores show higher $\mu \beta_{0}$ values than their related benzothiazolylidene systems. Different experimental techniques (e.g. IR, Raman, CV) 
showed a more polarized character for benzothiazolylidene chromophores, due to the higher electron-donating ability of the benzothiazole moiety compared to the pyran one. Thus, the change $\mathbf{P y} \rightarrow \mathbf{B z}$ in the more polarized shorter derivatives $\mathbf{0}$ results in a decreased NLO response, approaching the region B/C of the Marder's plot. ${ }^{3 \mathrm{~b}}$ For $\mathbf{1}$ derivatives, NLO responses are similar for $\mathbf{P y}$ and $\mathbf{B z}$ systems (with furanone $\mathbf{P h F u}$ ) or even higher for the latter (with acceptors $\mathbf{M e} \mathbf{e}_{2} \mathbf{F u}$ and $\mathbf{B u F u}$ ).

Measurements in DMF were also performed for model compounds Py1PhFu and Py1Me $\mathbf{M}_{2}$ Fu. The following experimental values $\left(10^{-48}\right.$ esu) were found: chromophore Py1PhFu: $1700(\mu \beta)$, $700\left(\mu \beta_{0}\right)$; chromophore Py1Me $\mathbf{F u}: 910(\mu \beta), 530\left(\mu \beta_{0}\right)$. Results show a decline of $\mu \beta_{0}$ in both cases, compared to those measured in dichloromethane (Table 5), indicating that these systems are left-handed chromophores (A/B region), with the neutral form predominating in this solvent polarity range.

The calculated $\mu \beta_{0}$ values (HF/6-31G*, Table 5) are in reasonably good consonance with the experimental ones, and they essentially reproduce the trends experimentally observed in terms of the effects of the acceptor $\mathbf{P h F u}$ and the length of the polyenic chain. Concerning the influence of the donor group, theoretical calculations do not predict the experimental observed effects for series $\mathbf{0}$, although differences are generally small.

Finally, it could also be instructive to compare the NLO properties of the compounds herein reported to those of related derivatives featuring other acceptor moities, including those previously mentioned in the X-ray section (See Figures 7 and 8 and Table 6). 
Figure 7: Structures of related chromophores to series Py0 previously reported.<smiles>CC1=CC(=CC=[V])OC(C(C)(C)C)=CC1=CCC(C)(C)C</smiles>

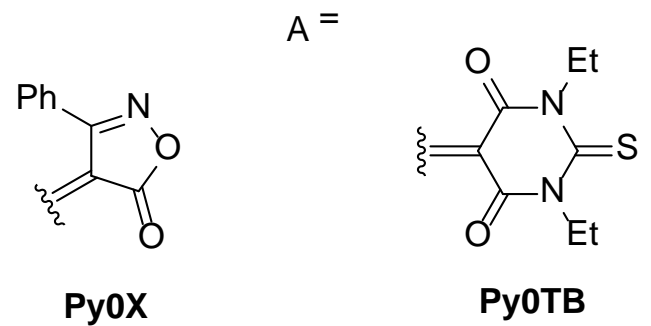<smiles>C/C=c1/sc(=C(C#N)C#N)nc1-c1ccccc1</smiles>

Py0Tz<smiles>CC1=C(C#N)C(=C(C#N)C#N)OC1(C)C</smiles>

Py0TCF

Figure 8: Structures of related chromophores to series Py1 previously reported.<smiles>CC(C)(C)C1=CC(=C/C=C/C=[V])C=C(C(C)(C)C)O1</smiles>

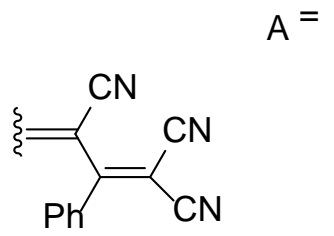

Py1tricN<smiles>C/C=c1/sc(=C(C#N)C#N)nc1-c1ccccc1</smiles>

Py1Tz<smiles>C=c1ccc(=C(C#N)C#N)s1</smiles>

Py1TF<smiles>CC1=C(C#N)C(=C(C#N)C#N)OC1(C)C</smiles>

Py1TCF 
TABLE 6. NLO Properties for related chromophores to series Py

\begin{tabular}{|c|c|c|c|}
\hline Compd & Ref. & $\begin{array}{c}\mu \beta_{0}{ }^{a} \\
\left(10^{-48} \text { esu }\right)\end{array}$ & $\begin{array}{l}\lambda_{\max }{ }^{b} \\
(\mathrm{~nm})\end{array}$ \\
\hline Py0X & $10 \mathrm{~b}$ & +64 & \\
\hline Рy0TB & $10 \mathrm{~b}$ & -60 & \\
\hline Py0Tz & $10 c$ & -450 & \\
\hline Py0TCF & $10 \mathrm{~b}$ & +310 & 592, 639 \\
\hline Py1triCN & $10 \mathrm{~b}$ & +670 & \\
\hline Py1TF & 23 & +1370 & 658, 709, 788 \\
\hline Py1TZ & $10 \mathrm{c}$ & -1010 & \\
\hline Py1TCF & $10 \mathrm{~b}$ & +1520 & 675,740 \\
\hline \multicolumn{4}{|c|}{$\begin{array}{l}{ }^{a} \text { Experimental } \mu \beta_{0} \text { values in } \mathrm{CH}_{2} \mathrm{Cl}_{2} \text { calculated using the } \\
\text { wo-level model from } \mu \beta \text { measured by EFISHG at } 1907 \mathrm{~nm} \text {. } \\
\text { In } \mathrm{CH}_{2} \mathrm{Cl}_{2} \text {. }\end{array}$} \\
\hline
\end{tabular}

Thus, analogue of Py0PhFu with 3-phenyl-5-isoxazolone as acceptor, ${ }^{10 \mathrm{~b}} \mathbf{P y 0 X}$ shows a lower $\mu \beta_{0}$ value than $\mathbf{P y 0 P h F u}$, in agreement with a more polarized structure in solution, apart from the solid state (See X-Ray section). Other chromophores with powerful electronwithdrawing ends have also lower nonlinearities than Py0PhFu, even negative figure of merit, as in the case of the thiobarbiturate derivative Py0TB. ${ }^{10 b}$

In the same way, Py1triCN with 1,1,3-tricyano-2-phenylpropene, ${ }^{10 \mathrm{~b}}$ has a lower response than Py1PhFu, in line with a less alternated structure in solution (also in the solid state, as disclosed by X-ray crystallography).

Series with a 2-dicyanomethylenethiazole moiety ${ }^{10 c}$ as end group (Py0TZ, Figure 7 and Py1TZ, Figure 8) show negative values of $\mu \beta_{0}$, being essentially zwitterionic molecules that show negative solvatochromism. Nevertheless, absolute values are slightly lower compared to those of Py0PhFu and Py1PhFu respectively. 
As it has been stated in the X-ray section, Py1PhFu and its equivalent with 2dicyanomethylenethiophene ${ }^{23}$ Py1TF have similar structures, and it is noteworthy that Py1PhFu, while being more transparent (Table 4), shows even slightly higher NLO response.

The pyranylidene-derived Fischer carbene complexes reported by Caro, ${ }^{10 a, 38}$ with the same length of the $\pi$-relay than the chromophores herein studied show lower $\mu \beta_{1907}$ values than those of compounds Py0(PhFu,Me $\mathbf{F u}, \mathrm{BuFu})$ and $\mathrm{Py} 1\left(\mathrm{PhFu}, \mathrm{Me}_{2} \mathrm{Fu}, \mathrm{BuFu}\right)$.

On the other hand, as it has been mentioned in the Introduction, furanone $\mathbf{M e} \mathbf{F}_{2} \mathbf{F u}$ can be viewed as a "weak version” of the efficient TCF acceptor, and thus, derivatives Py0Me $\mathbf{P} \mathbf{F u}$ and $\mathbf{P y} 1 \mathrm{Me}_{2} \mathrm{Fu}$ can be compared to their previously reported analogues with $\mathrm{TCF}{ }^{10 \mathrm{~b}}$ Py0TCF and Py1TCF respectively (Figures 7 and 8). For the shorter derivatives 0, and in consequence, with more polarized structures, a higher nonlinearity, which is accompanied by a hypsochromic shift of the absorption bands is found for $\mathbf{P y 0 M e} 2 \mathbf{F u}$. For derivatives 1, with less polarized structures, compound Py1TCF, bearing the stronger acceptor shows a higher NLO response, but $\mathbf{P y} \mathbf{1} \mathbf{M e}_{2} \mathbf{F u}$ is also more transparent (Table 4).

Chromophores of series $\mathbf{B z}$ show positive figure of merit $\mu \beta_{0}$, contrary to their equivalents with 2-dicyanomethylenethiazole as acceptor. ${ }^{11 \mathrm{e}}$ The latter are right-handed chromophores, with a predominantly zwitterionic form for their ground electronic state. Although these were measured in DMSO due to their limited solubility in $\mathrm{CH}_{2} \mathrm{Cl}_{2}$, the qualitative experimental results in the latter solvent also pointed to negative nonlinearities. Considering the use of different solvents, values for compounds $\mathbf{B z O}\left(\mathbf{P h F u}, \mathbf{M e}_{2} \mathbf{F u}, \mathbf{B u F u}\right)$ and $\mathbf{B z 1}\left(\mathbf{P h F u}, \mathbf{M e}_{2} \mathbf{F u}, \mathbf{B u F u}\right)$ are similar or even higher in absolute values. 
Further comparisons with benzothiazolylidene chromophores bearing other acceptors are somewhat restricted by the different experimental setups used in the measurement of the corresponding second-order NLO properties (Hyper Raleigh Scattering (HRS) as technique, other laser wavelength and/or other solvents) ${ }^{11 \mathrm{~b}-c, 32,39}$ or by the structure of merocyanine featuring a quite different $\pi$-spacer. ${ }^{11 \mathrm{~d}}$

Thus, in short, the NLO properties of furanone-containing merocyanines herein studied compare favorably to those of related chromophores bearing more efficient acceptor units.

\section{Conclusion}

$\Delta^{\alpha, \beta}$-butenolides (or 2(5H)-furanones) have been used as acceptor ends in the synthesis of D- $\pi$-A systems with second-order NLO properties. All derivatives exist as a resonance hybrid of the neutral and zwitterionic forms, with different molecular polarization (and thus, different properties), depending on the donor unit and the butenolide fragment.

X-ray crystallography, NMR data and calculated NBO charges reveal that polarization of the chromophores studied increases in the order: systems $\mathbf{M e}_{2} \mathbf{F u}<$ systems $\mathbf{B u F u}<$ systems PhFu. Moreover, derivatives of proaromatic butenolide $\mathbf{P h F u}$ show the easiest reduction process and the highest absorption wavelength.

The benzothiazolylidene moiety has a better electron-donating ability compared to that of the pyranylidene ring, as disclosed by X-ray studies, theoretical data, IR, Raman and CV. This fact gives rise to a more effective polarization for chromophores of $\mathbf{B z}$ series with an important contribution, for compounds bearing the proaromatic furanones $\mathbf{P h F u}, \mathbf{B u F u}$, of the canonical form in which furan gets aromatic. Furthermore, unlike most D- $\pi$-A systems, 
the degree of ICT in derivatives $\mathbf{B z}$ increases on lengthening the $\pi$-spacer, as revealed by IR and Raman spectroscopies.

All compounds display positive $\mu \beta_{0}$ values, showing chromophores endowed with the proaromatic butenolide $\mathbf{P h F u}$ as acceptor moiety the best NLO responses. The change $\mathbf{P y}$ $\rightarrow \mathbf{B z}$ results in lower second-order nonlinearities for derivatives $\mathbf{0}$, due to the more polarized structures for derivatives Bz. Incorporation of furanones $\mathbf{P h F u}, \mathbf{M e}_{2} \mathbf{F u}, \mathbf{B u F u}$ leads to moderately-polarized structures with higher NLO responses (accompanied sometimes by a better transparency) when compared to other chromophores bearing more efficient acceptors. Taking these data into account, $2(5 H)$-furanones become suitable acceptor moieties for the preparation of novel structures with an effective polarization and upgraded second-order NLO responses.

\section{Experimental Section}

General information: See the Supporting Information.

Starting materials: Compounds PhFu, $,{ }^{14} \mathbf{P y 0},{ }^{17} \mathbf{P y 1},{ }^{10 \mathrm{~b}} \mathbf{B z 0},{ }^{20}$ and $\mathbf{B z 1}{ }^{20}$ were prepared as previously described. Acceptor $\mathbf{M e}_{2} \mathbf{F u}$ was prepared by following the same procedure reported for the corresponding analogue with methyl and ethyl groups in C5. ${ }^{15 b}$

4-tert-butyl-2-oxo-2,5-dihydrofuran-3-carbonitrile (BuFu). 1-bromopinacolone (2 mL, $14.9 \mathrm{mmol})$ and cyanoacetic acid $(1.26 \mathrm{~g}, 14.9 \mathrm{mmol})$ were added to a solution of $\mathrm{NaOH}$ (0.60 g, $14.9 \mathrm{mmol})$ in ethanol/water $(22 \mathrm{~mL} / 5 \mathrm{~mL})$ under an argon atmosphere. The reaction mixture was heated at reflux for $6 \mathrm{~h} 30 \mathrm{~min}$ (TLC monitoring). The final red solution was evaporated and the crude product dissolved in EtOAc $(20 \mathrm{~mL})$. The organic layer was washed with water $(2 \times 10 \mathrm{~mL})$, dried over $\mathrm{MgSO}_{4}$ and evaporated. The resulting orange oil 
was purified by flash chromatography (silica gel) with $\mathrm{CH}_{2} \mathrm{Cl}_{2}$ as the eluent, obtaining first, compound BuFu (4-tert-butyl-2-oxo-2,5-dihydrofuran-3-carbonitrile: $884 \mathrm{mg}, 36 \%$ ) as a yellow oil which solidified on standing, then 1 (3,3-dimethyl-2-oxobutyl cyanoacetate: 317 mg, 10\%) as a yellowish solid. A second fraction of compound BuFu was obtained by cyclisation of $\mathbf{1}$ as follows: 3,3-dimethyl-2-oxobutyl cyanoacetate $\mathbf{1}$ (317 mg, $1.73 \mathrm{mmol}$ ) was added to a solution of $\mathrm{Na}(20 \mathrm{mg}, 0.87 \mathrm{mmol})$ in $\mathrm{EtOH}(2 \mathrm{~mL})$ under an argon atmosphere. The mixture was stirred for $24 \mathrm{~h}$ turning from orange to red. $\mathrm{HCl} 1 \mathrm{~N}$ (2.9 mL, $2.9 \mathrm{mmol})$ was added, and the aqueous layer was extracted with $\mathrm{CH}_{2} \mathrm{Cl}_{2}(3 \times 10 \mathrm{~mL})$, and the resulting organic layer was dried over $\mathrm{MgSO}_{4}$ and evaporated. The crude oil was purified by flash chromatography (silica gel) with $\mathrm{CH}_{2} \mathrm{Cl}_{2} /$ hexane 9.5:0.5 as the eluent to give $\mathbf{B u F u}$ (57 mg, 20\%).

4-tert-butyl-2-oxo-2,5-dihydrofuran-3-carbonitrile (BuFu). Mp 60-63 ${ }^{\circ} \mathrm{C}$ (Ref. ${ }^{16}$ : mp $\left.64{ }^{\circ} \mathrm{C}\right) ;{ }^{1} \mathrm{H}$ NMR (400 MHz, $\left.\mathrm{CDCl}_{3}\right): \delta=4.98$ (s, 2H), $1.41 \mathrm{ppm}$ (s, 9H); ${ }^{13} \mathrm{C}$ NMR (75 $\left.\mathrm{MHz}, \mathrm{CDCl}_{3}\right): \delta=188.2,168.0,111.1,110.0,71.1,35.4,28.4 \mathrm{ppm}$; IR (neat): $\bar{v}=2975$ $\left(\mathrm{C}_{\mathrm{sp} 3}-\mathrm{H}\right), 2238(\mathrm{C} \equiv \mathrm{N}), 1776(\mathrm{C}=\mathrm{O}), 1626 \mathrm{~cm}^{-1}(\mathrm{C}=\mathrm{C})$; HRMS $\left(\mathrm{ESI}^{+}\right): \mathrm{m} / \mathrm{z}[\mathrm{M}+\mathrm{H}]^{+}$calcd for $\mathrm{C}_{9} \mathrm{H}_{12} \mathrm{NO}_{2}$ 166.0863; found 166.0894; $[\mathrm{M}+\mathrm{Na}]^{+}$calcd for $\mathrm{C}_{9} \mathrm{H}_{11} \mathrm{NNaO}_{2}$ 188.0682; found 188.0698; Anal. Calcd for $\mathrm{C}_{9} \mathrm{H}_{11} \mathrm{NO}_{2}$ : C 65.44, H 6.71, N 8.48. Found: C 65.19, H 6.50, N, 8.56.

3,3-dimethyl-2-oxobutyl cyanoacetate (1). $\mathrm{Mp} 46-51{ }^{\circ} \mathrm{C} ;{ }^{1} \mathrm{H} \mathrm{NMR}\left(400 \mathrm{MHz}, \mathrm{CDCl}_{3}\right)$ : $\delta=4.99$ (s, 2H), 3.60 (s, 2H), 1.20 ppm (s, 9H); ${ }^{13} \mathrm{C}$ NMR (100 MHz, $\left.\mathrm{CDCl}_{3}\right): \delta=206.3$, 162.6, 112.7, 66.1, 42.7, 26.0, 24.3 ppm; IR (Nujol): $\bar{v}=2261(\mathrm{C} \equiv \mathrm{N}), 1759(\mathrm{C}=\mathrm{O}), 1724$ $\mathrm{cm}^{-1}(\mathrm{C}=\mathrm{O})$; HRMS (ESI $\left.{ }^{+}\right): \mathrm{m} / \mathrm{z} \quad[\mathrm{M}+\mathrm{Na}]^{+}$calcd for $\mathrm{C}_{9} \mathrm{H}_{13} \mathrm{NNaO}_{3}$ 206.0788; found 
206.0772; Anal. Calcd for $\mathrm{C}_{9} \mathrm{H}_{13} \mathrm{NO}_{3}$ : C 59.00, H 7.15, N 7.65. Found: C 58.75, H 7.32, N, 7.85 .

Compounds $\mathrm{Py0}\left(\mathrm{PhFu}, \mathrm{Me}_{2} \mathrm{Fu}, \mathrm{BuFu}\right)$. General procedure. To a solution of aldehyde Py0 (111 $\mathrm{mg}, 0.48 \mathrm{mmol})$ in absolute ethanol $(5 \mathrm{~mL})$ the corresponding acceptor ( $\mathbf{P h F u}, \mathbf{M e}_{2} \mathbf{F u}, \mathbf{B u F u}$ ) (0.48 mmol) was added. (For the reaction with acceptor $\mathbf{M e}_{2} \mathbf{F u}$ piperidine (one drop) was added). The mixture was refluxed under argon with exclusion of light (TLC monitoring). In the case of PyOPhFu and Py0Me $2 \mathbf{F u}$, after cooling, the resulting solid was isolated by filtration, washed with cold ethanol and a cold mixture of pentane/ $\mathrm{CH}_{2} \mathrm{Cl}_{2}$ 9.5:0.5. In the case of $\mathbf{P y 0 B u F u}$, the solvent was evaporated and the crude product was purified by flash chromatography (silica gel).

\section{(Z)-5-(2-(2,6-di-tert-butyl-4H-pyran-4-ylidene)ethylidene)-2-oxo-4-phenyl-2,5-}

dihydrofuran-3-carbonitrile (Py0PhFu). Reaction time: 5 hours. Evaporation of the filtrate and flash chromatography (silica gel) with $\mathrm{CH}_{2} \mathrm{Cl}_{2}$ as the eluent gave a second fraction. Yield: dark blue solid (118 mg; 62\%). Mp 241-246 ${ }^{\circ} \mathrm{C} ;{ }^{1} \mathrm{H}$ NMR (400 MHz, $\left.\mathrm{CDCl}_{3}\right): \delta=7.62-7.53(\mathrm{~m}, 5 \mathrm{H}), 6.67(\mathrm{~d}, J=13.1 \mathrm{~Hz}, 1 \mathrm{H}), 6.18(\mathrm{~d}, J=1.8 \mathrm{~Hz}, 1 \mathrm{H}), 6.13(\mathrm{~d}$, $J=13.1 \mathrm{~Hz}, 1 \mathrm{H}), 6.07$ (d, $J=1.8 \mathrm{~Hz}, 1 \mathrm{H}), 1.26$ (s, 9H), $1.24 \mathrm{ppm}(\mathrm{s}, 9 \mathrm{H}) ;{ }^{13} \mathrm{C}$ NMR (100 $\left.\mathrm{MHz}, \mathrm{CDCl}_{3}\right): \delta=169.6,169.3,165.7,157.6,145.2,141.3,131.1,129.2,128.9,120.8$, 114.0, 113.7, 108.5, 107.5, 100.3, 91.1, 36.3, 36.1, 27.8 ppm; IR (Nujol): $\bar{v}=2213(\mathrm{C} \equiv \mathrm{N})$, $1739(\mathrm{C}=\mathrm{O}), 1655(\mathrm{C}=\mathrm{C}), 1589(\mathrm{C}=\mathrm{C}), 1567 \mathrm{~cm}^{-1}(\mathrm{C}=\mathrm{C}) ; \mathrm{HRMS}\left(\mathrm{ESI}^{+}\right): \mathrm{m} / \mathrm{z}[\mathrm{M}+\mathrm{H}]^{+}$calcd for $\mathrm{C}_{26} \mathrm{H}_{28} \mathrm{NO}_{3}$ 402.2064; found 402.2062; $[\mathrm{M}+\mathrm{Na}]^{+}$calcd for $\mathrm{C}_{26} \mathrm{H}_{27} \mathrm{NNaO}_{3}$ 424.1883; found 424.1861; $[2 \mathrm{M}+\mathrm{H}]^{+}$calcd for $\mathrm{C}_{52} \mathrm{H}_{55} \mathrm{~N}_{2} \mathrm{O}_{6}$ 803.4055; found 803.4050; [2M+Na $]^{+}$ calcd for $\mathrm{C}_{52} \mathrm{H}_{54} \mathrm{~N}_{2} \mathrm{NaO}_{6}$ 825.3874; found 825.3862; Anal. Calcd for $\mathrm{C}_{26} \mathrm{H}_{27} \mathrm{NO}_{3}$ : C 77.78, H 6.78, N 3.49. Found: C 78.01, H 6.54, N 3.71. 


\section{(E)-4-(3-(2,6-di-tert-butyl-4H-pyran-4-ylidene)prop-1-enyl)-5,5-dimethyl-2-oxo-2,5-}

dihydrofuran-3-carbonitrile (Py0Me 2 Fu). Reaction time: 16h30min. Evaporation of the filtrate and flash chromatography (silica gel) with $\mathrm{CH}_{2} \mathrm{Cl}_{2}$ as the eluent gave a second fraction. Yield: bright dark violet solid (122 mg; 69\%). Mp 203-206 ${ }^{\circ} \mathrm{C} ;{ }^{1} \mathrm{H}$ NMR (400 $\left.\mathrm{MHz}, \mathrm{CDCl}_{3}\right): \delta=8.36\left(\mathrm{dd}, J_{1}=14.5 \mathrm{~Hz}, J_{2}=12.4 \mathrm{~Hz}, 1 \mathrm{H}\right), 6.47(\mathrm{~d}, J=1.9 \mathrm{~Hz}, 1 \mathrm{H}), 5.96$ (d, $J=1.9 \mathrm{~Hz}, 1 \mathrm{H}), 5.79$ (d, $J=14.5 \mathrm{~Hz}, 1 \mathrm{H}), 5.68$ (d, $J=12.4 \mathrm{~Hz}, 1 \mathrm{H}), 1.52$ (s, 6H), 1,28 (s, 9H), 1,25 ppm (s, 9H); ${ }^{13} \mathrm{C}$ NMR (100 MHz, $\left.\mathrm{CDCl}_{3}\right): \delta=176.4,169.0,168.9,168.3$, 145.6, 143.8, 115.6, 111.7, 108.9, 106.4, 100.7, 87.1, 86.0, 36.2, 36.0, 27.8, 26.0 ppm; IR (Nujol): $\quad \bar{v}=2206(\mathrm{C} \equiv \mathrm{N}), 1738(\mathrm{C}=\mathrm{O}), 1661(\mathrm{C}=\mathrm{C}), 1596(\mathrm{C}=\mathrm{C}), 1544 \mathrm{~cm}^{-1}(\mathrm{C}=\mathrm{C})$; HRMS (ESI $\left.{ }^{+}\right): m / z[M+H]^{+}$calcd for $\mathrm{C}_{23} \mathrm{H}_{30} \mathrm{NO}_{3}$ 368.2220; found 368.2196; [M+Na ${ }^{+}$ calcd for $\mathrm{C}_{23} \mathrm{H}_{29} \mathrm{NNaO}_{3} 390.2040$; found 390.2012; Anal. Calcd for $\mathrm{C}_{23} \mathrm{H}_{29} \mathrm{NO}_{3}$ : C 75.17, $\mathrm{H}$ 7.95, N 3.81. Found: C 75.03, H 8.13, N, 4.06.

\section{(Z)-4-tert-butyl-5-(2-(2,6-di-tert-butyl-4H-pyran-4-ylidene)ethylidene)-2-oxo-2,5-}

dihydrofuran-3-carbonitrile (Py0BuFu). Reaction time: 5h30min. Eluent chromatography: $\mathrm{CH}_{2} \mathrm{Cl}_{2} / \mathrm{Et}_{2} \mathrm{O}$ 9.9:0.1. After column, the resulting solid was washed with a cold mixture of pentane/ $\mathrm{CH}_{2} \mathrm{Cl}_{2}$ 9.5:0.5. Yield: dark violet solid (50 mg; 28\%). Mp 226$229{ }^{\circ} \mathrm{C} ;{ }^{1} \mathrm{H}$ NMR (400 MHz, $\left.\mathrm{CDCl}_{3}\right): \delta=6.98(\mathrm{~d}, J=12.6 \mathrm{~Hz}, 1 \mathrm{H}), 6.20$ (d, $J=1.9 \mathrm{~Hz}$, 1H), 6.04 (d, $J=12.6 \mathrm{~Hz}, 1 \mathrm{H}), 6.01$ (d, $J=1.9 \mathrm{~Hz}, 1 \mathrm{H}), 1.55$ (s, 9H), 1.28 (s, 9H), 1.25 ppm (s, 9H); ${ }^{13} \mathrm{C}$ NMR (100 MHz, $\left.\mathrm{CDCl}_{3}\right): \delta=168.9,168.5,167.7,166.1,143.7,141.2$, 120.7, 114.6, 107.8, 107.1, 99.7, 93.5, 36.2, 36.0, 35.1, 31.3, 27.8 ppm; IR (Nujol): $\bar{v}=$ $2215(\mathrm{C} \equiv \mathrm{N}), 1746(\mathrm{C}=\mathrm{O}), 1659(\mathrm{C}=\mathrm{C}), 1588(\mathrm{C}=\mathrm{C}), 1574(\mathrm{C}=\mathrm{C}), 1512 \mathrm{~cm}^{-1}(\mathrm{C}=\mathrm{C})$; HRMS (ESI $\left.{ }^{+}\right): m / z[M+H]^{+}$calcd for $\mathrm{C}_{24} \mathrm{H}_{32} \mathrm{NO}_{3}$ 382.2377; found 382.2362; [M+Na ${ }^{+}$ calcd for $\mathrm{C}_{24} \mathrm{H}_{31} \mathrm{NNaO}_{3}$ 404.2196; found 404.2174; $[\mathrm{M}+\mathrm{K}]^{+}$calcd for $\mathrm{C}_{24} \mathrm{H}_{31} \mathrm{KNO}_{3}$ 
420.1936; found 420.1922; Anal. Calcd for $\mathrm{C}_{24} \mathrm{H}_{31} \mathrm{NO}_{3}$ : C 75.56, H 8.19, N 3.67. Found: C 75.34, H 7.98, N, 3.83.

Compounds Py1(PhFu,Me $2 \mathrm{Fu}, \mathrm{BuFu})$. General procedure. To a solution of aldehyde Py1 (110 $\mathrm{mg}, 0.42 \mathrm{mmol})$ in absolute ethanol $(5 \mathrm{~mL})$ the corresponding acceptor ( $\mathbf{P h F u}, \mathbf{M e}_{2} \mathbf{F u}, \mathbf{B u F u}$ ) (0.42 mmol) was added. (For the reaction with acceptor $\mathbf{M e}_{2} \mathbf{F u}$ piperidine (one drop) was added). The mixture was refluxed under argon with exclusion of light (TLC monitoring). After cooling, the solvent was evaporated and the crude product was purified by flash chromatography (silica gel) with $\mathrm{CH}_{2} \mathrm{Cl}_{2}$ as the eluent. The resulting solid was washed with a cold mixture of pentane/ $\mathrm{CH}_{2} \mathrm{Cl}_{2}$ 9.5:0.5.

(Z)-5-((E)-4-(2,6-di-tert-butyl-4H-pyran-4-ylidene)but-2-enylidene)-2-oxo-4-phenyl2,5-dihydrofuran-3-carbonitrile (Py1PhFu). Reaction time: 8h15min. Yield: dark blue solid (43 mg; 24\%). Mp 186-190 ${ }^{\circ} \mathrm{C} ;{ }^{1} \mathrm{H}$ NMR (400 MHz, $\mathrm{CDCl}_{3}$ ): $\delta=7.61-7.53$ (m, 5H), $7.13\left(\mathrm{dd}, J_{1}=13.4 \mathrm{~Hz}, J_{2}=12.6 \mathrm{~Hz}, 1 \mathrm{H}\right), 6.65\left(\mathrm{dd}, J_{1}=13.4 \mathrm{~Hz}, J_{2}=12.2 \mathrm{~Hz}, 1 \mathrm{H}\right), 6.46$ (dd, $\left.J_{1}=12.2 \mathrm{~Hz}, J_{2}=0.4 \mathrm{~Hz}, 1 \mathrm{H}\right), 6.24(\mathrm{~d}, J=1.8 \mathrm{~Hz}, 1 \mathrm{H}), 5.89$ (d, $\left.J=1.8 \mathrm{~Hz}, 1 \mathrm{H}\right), 5.73$ (d, $J=12.6 \mathrm{~Hz}, 1 \mathrm{H}), 1.24(\mathrm{~s}, 9 \mathrm{H}), 1.23 \mathrm{ppm}(\mathrm{s}, 9 \mathrm{H}) ;{ }^{13} \mathrm{C}$ NMR $\left(100 \mathrm{MHz}, \mathrm{CDCl}_{3}\right): \delta=$ 167.7, 167.6, 165.4, 158.1, 142.6, 142.4, 141.7, 131.2, 129.2, 128.9, 128.7, 125.9, 120.6, 114.0, 113.4, 106.5, 100.0, 92.6, 36.1, 35.9, 27.9, 27.8 ppm; IR (Nujol): $\bar{v}=2217(\mathrm{C} \equiv \mathrm{N})$, $1742(\mathrm{C}=\mathrm{O}), 1657(\mathrm{C}=\mathrm{C}), 1557(\mathrm{C}=\mathrm{C}), 1518 \mathrm{~cm}^{-1}(\mathrm{C}=\mathrm{C})$; HRMS $\left(\mathrm{ESI}^{+}\right): \mathrm{m} / \mathrm{z}[\mathrm{M}+\mathrm{H}]^{+}$calcd for $\mathrm{C}_{28} \mathrm{H}_{30} \mathrm{NO}_{3}$ 428.2220; found 428.2209; $[\mathrm{M}+\mathrm{Na}]^{+}$calcd for $\mathrm{C}_{28} \mathrm{H}_{29} \mathrm{NNaO}_{3}$ 450.2040; found 450.2011; [M+K] $]^{+}$calcd for $\mathrm{C}_{28} \mathrm{H}_{29} \mathrm{KNO}_{3}$ 466.1779; found 466.1748; Anal. Calcd for $\mathrm{C}_{28} \mathrm{H}_{29} \mathrm{NO}_{3}$ : C 78.66, H 6.84, N 3.28. Found: C 78.82, H 6.74, N 3.51.

4-((1E,3E)-5-(2,6-di-tert-butyl-4H-pyran-4-ylidene)penta-1,3-dienyl)-5,5-dimethyl-2oxo-2,5-dihydrofuran-3-carbonitrile (Py1Me 2 Fu). Reaction time: 9 hours. Yield: dark 
green solid (33 mg; 20\%). Mp 232-235 ${ }^{\circ} \mathrm{C} ;{ }^{1} \mathrm{H}$ NMR (400 MHz, $\left.\mathrm{CDCl}_{3}\right): \delta=7.71$ (dd, $J_{1}=$ $\left.14.9 \mathrm{~Hz}, J_{2}=11.6 \mathrm{~Hz}, 1 \mathrm{H}\right), 7.19\left(\mathrm{dd}, J_{1}=13.8 \mathrm{~Hz}, J_{2}=12.5 \mathrm{~Hz}, 1 \mathrm{H}\right), 6.26(\mathrm{~d}, J=1.8 \mathrm{~Hz}$, 1H), $6.22\left(\mathrm{dd}, J_{1}=13.8 \mathrm{~Hz}, J_{2}=11.6 \mathrm{~Hz}, 1 \mathrm{H}\right), 6.00(\mathrm{~d}, J=14.9 \mathrm{~Hz}, 1 \mathrm{H}), 5.83(\mathrm{~d}, J=1.8$ Hz, 1H), 5.62 (d, $J=12.5 \mathrm{~Hz}, 1 \mathrm{H}), 1.56$ (s, 6H), 1,27 (s, 9H), 1,22 ppm (s, 9H); ${ }^{13} \mathrm{C}$ NMR $\left(100 \mathrm{MHz}, \mathrm{CDCl}_{3}\right): \delta=175.7,167.8,167.2,166.8,148.5,142.4,140.9,125.1,114.2$, 112.6, 112.4, 106.0, 99.7, 90.3, 86.3, 36.1, 35.7, 27.9, 27.7, 26.1 ppm; IR (Nujol): $\bar{v}=$ $2201(\mathrm{C} \equiv \mathrm{N}), 1742(\mathrm{C}=\mathrm{O}), 1662(\mathrm{C}=\mathrm{C}), 1576 \mathrm{~cm}^{-1}(\mathrm{C}=\mathrm{C}) ; \mathrm{HRMS}\left(\mathrm{ESI}^{+}\right): \mathrm{m} / \mathrm{z}[\mathrm{M}+\mathrm{H}]^{+}$calcd for $\mathrm{C}_{25} \mathrm{H}_{32} \mathrm{NO}_{3}$ 394.2377; found 394.2378; calcd for $[\mathrm{M}+\mathrm{Na}]^{+} \mathrm{C}_{25} \mathrm{H}_{31} \mathrm{NNaO}_{3}$ 416.2196; found 416.2177; Anal. Calcd for $\mathrm{C}_{25} \mathrm{H}_{31} \mathrm{NO}_{3}$ : C 76.30, H 7.94, N 3.56. Found: C 76.45, H 7.73, N 3.83.

\section{(Z)-4-tert-butyl-5-((E)-4-(2-(2,6-di-tert-butyl-4H-pyran-4-ylidene)but-2-enylidene)-2-} oxo-2,5-dihydrofuran-3-carbonitrile (Py1BuFu). Reaction time: 9 hours. Yield: dark blue solid (39 mg; 23\%). Mp 127-130 ${ }^{\circ} \mathrm{C} ;{ }^{1} \mathrm{H}$ NMR (400 MHz, $\mathrm{CDCl}_{3}$ ): $\delta=7.08$ (dd, $J_{1}=$ $\left.13.7 \mathrm{~Hz}, J_{2}=12.5 \mathrm{~Hz}, 1 \mathrm{H}\right), 6.73(\mathrm{~d}, J=11.9 \mathrm{~Hz}, 1 \mathrm{H}), 6.59\left(\mathrm{dd}, J_{1}=13.7 \mathrm{~Hz}, J_{2}=11.9 \mathrm{~Hz}\right.$, 1H), 6.23 (d, $J=1.6 \mathrm{~Hz}, 1 \mathrm{H}), 5.84$ (d, $J=1.6 \mathrm{~Hz}, 1 \mathrm{H}), 5.68$ (d, $J=12.5 \mathrm{~Hz}, 1 \mathrm{H}), 1.54$ (s, 9H), 1.26 (s, 9H), $1.22 \mathrm{ppm}(\mathrm{s}, 9 \mathrm{H}) ;{ }^{13} \mathrm{C}$ NMR (100 MHz, $\left.\mathrm{CDCl}_{3}\right): \delta=168.3,167.0,166.8$, 165.7, 142.5, 140.9, 140.3, 125.7, 120.5, 114.2, 113.7, 106.2, 99.7, 95.1, 36.1, 35.8, 31.2, 29.7, 27.9, 27.8 ppm; IR (Nujol): $\bar{v}=2219(\mathrm{C} \equiv \mathrm{N}), 1749(\mathrm{C}=\mathrm{O}), 1659(\mathrm{C}=\mathrm{C}), 1558 \mathrm{~cm}^{-1}$ $(\mathrm{C}=\mathrm{C})$; HRMS $\left(\mathrm{ESI}^{+}\right): \mathrm{m} / \mathrm{z}[\mathrm{M}+\mathrm{H}]^{+}$calcd for $\mathrm{C}_{26} \mathrm{H}_{34} \mathrm{NO}_{3}$ 408.2533; found 408.2514; $[\mathrm{M}+\mathrm{Na}]^{+}$calcd for $\mathrm{C}_{26} \mathrm{H}_{33} \mathrm{NNaO}_{3}$ 430.2353; found 430.2323; $[\mathrm{M}+\mathrm{K}]^{+}$calcd for $\mathrm{C}_{26} \mathrm{H}_{33} \mathrm{KNO}_{3}$ 446.2092; found 446.2055; Anal. Calcd for $\mathrm{C}_{26} \mathrm{H}_{33} \mathrm{NO}_{3}$ : C 76.62, H 8.16, N 3.44. Found: C 76.39, H 8.45, N 3.66. 
Compounds Bzo(PhFu,Me $\left.\mathbf{M e}_{2} \mathbf{F u}, \mathrm{BuFu}\right)$. General procedure. To a solution of benzothiazolium salt Bz0 (60 mg; $0.15 \mathrm{mmol}$ ) and the corresponding acceptor (PhFu,Me 2 Fu,BuFu) (0.15 mmol) in ethanol (1.6 mL), triethylamine (0.27 mL, 1.94 mmol) was added. The mixture was refluxed under argon with exclusion of light (TLC monitoring). In the case of $\mathbf{B z 0 P h F u}$, after cooling, the resulting solid was isolated by filtration, washed with cold ethanol and a cold mixture of pentane/ $\mathrm{CH}_{2} \mathrm{Cl}_{2}$ 9.5:0.5. In the case of $\mathbf{B z O M e}_{2} \mathbf{F u}, \mathbf{B z O B u F u}$, the solvent was evaporated and the crude product was purified by flash chromatography (silica gel).

\section{(Z)-5-((Z)-2-(3-ethylbenzothiazol-2(3H)-ylidene)ethylidene)-2-oxo-4-phenyl-2,5-}

dihydrofuran-3-carbonitrile (Bz0PhFu). Reaction time: 25 min. Yield: violet to greyish solid (32 mg; 59\%). Mp 291-293 ${ }^{\circ} \mathrm{C}$ (Ref. ${ }^{14}$ : mp 279-281 ${ }^{\circ} \mathrm{C}$ ); ${ }^{1} \mathrm{H}$ NMR (400 MHz, $\left.\mathrm{CDCl}_{3}\right): \delta=7.63-7.53(\mathrm{~m}, 5 \mathrm{H}), 7.50\left(\mathrm{dd}, J_{1}=7.9 \mathrm{~Hz}, J_{2}=1.0 \mathrm{~Hz}, 1 \mathrm{H}\right), 7.42\left(\mathrm{ddd}, J_{1}=8.4\right.$ $\left.\mathrm{Hz}, J_{2}=7.6 \mathrm{~Hz}, J_{3}=1.0 \mathrm{~Hz}, 1 \mathrm{H}\right), 7.23\left(\mathrm{ddd}, J_{1}=7.9 \mathrm{~Hz}, J_{2}=7.6 \mathrm{~Hz}, J_{3}=0.9 \mathrm{~Hz}, 1 \mathrm{H}\right)$, $7.17\left(\mathrm{dd}, J_{1}=8.4 \mathrm{~Hz}, J_{2}=0.9 \mathrm{~Hz}, 1 \mathrm{H}\right), 6.62(\mathrm{~d}, J=12.6 \mathrm{~Hz}, 1 \mathrm{H}), 6.22(\mathrm{~d}, J=12.6 \mathrm{~Hz}, 1 \mathrm{H})$, $4.14(\mathrm{q}, J=7.3 \mathrm{~Hz}, 2 \mathrm{H}), 1.44 \mathrm{ppm}(\mathrm{t}, J=7.3 \mathrm{~Hz}, 3 \mathrm{H}) ;{ }^{13} \mathrm{C}$ NMR $\left(100 \mathrm{MHz}, \mathrm{CDCl}_{3}\right): \delta=$ $166.7,160.0,155.4,141.2,138.3,130.8,129.4,129.2,128.9,127.7,124.7,124.3,123.8$, 122.2, 114.5, 111.1, 104.7, 92.2, 41.0, 12.2 ppm; IR (Nujol): $\bar{v}=2207(\mathrm{C} \equiv \mathrm{N}), 1722$ $\left.(\mathrm{C}=\mathrm{O}), 1691(\mathrm{C}=\mathrm{C}), 1594(\mathrm{C}=\mathrm{C}), 1576(\mathrm{C}=\mathrm{C}), 1531 \mathrm{~cm}^{-1}(\mathrm{C}=\mathrm{C}) ; \mathrm{HRMS}_{(\mathrm{ESI}}^{+}\right): \mathrm{m} / \mathrm{z}$ $[\mathrm{M}+\mathrm{H}]^{+}$calcd for $\mathrm{C}_{22} \mathrm{H}_{17} \mathrm{~N}_{2} \mathrm{O}_{2} \mathrm{~S}$ 373.1005; found 373.0988; [M+Na ${ }^{+}$calcd for $\mathrm{C}_{22} \mathrm{H}_{16} \mathrm{~N}_{2} \mathrm{NaO}_{2} \mathrm{~S}$ 395.0825; found 395.0803; Anal. Calcd for $\mathrm{C}_{22} \mathrm{H}_{16} \mathrm{~N}_{2} \mathrm{O}_{2} \mathrm{~S}$ : C 70.95, H 4.33, N 7.52. Found: C 71.04, H 4.05, N 7.58.

4-((1E,3Z)-3-(3-ethylbenzothiazol-2(3H)-ylidene)prop-1-enyl)-5,5-dimethyl-2-oxo2,5-dihydrofuran-3-carbonitrile (Bz0Me $\mathbf{F u})$. Reaction time: 35 min. Eluent 
chromatography: $\mathrm{CH}_{2} \mathrm{Cl}_{2} / \mathrm{Et}_{2} \mathrm{O}$ 9.6:0.4. Yield: dark violet solid (26 mg; 52\%). Mp 248$251{ }^{\circ} \mathrm{C} ;{ }^{1} \mathrm{H}$ NMR (400 MHz, $\left.\mathrm{CD}_{3} \mathrm{COCD}_{3}\right): \delta=8.12\left(\mathrm{dd}, J_{1}=13.8 \mathrm{~Hz}, J_{2}=12.6 \mathrm{~Hz}, 1 \mathrm{H}\right)$, 7.85 (ddd, $\left.J_{1}=7.9 \mathrm{~Hz}, J_{2}=1.1 \mathrm{~Hz}, J_{3}=0.6 \mathrm{~Hz}, 1 \mathrm{H}\right), 7.52-7.45(\mathrm{~m}, 2 \mathrm{H}), 7.30$ (ddd, $J_{1}=7.9$ $\left.\mathrm{Hz}, J_{2}=6.1 \mathrm{~Hz}, J_{3}=2.3 \mathrm{~Hz}, 1 \mathrm{H}\right), 6.20(\mathrm{~d}, J=12.6 \mathrm{~Hz}, 1 \mathrm{H}), 5.97(\mathrm{~d}, J=13.8 \mathrm{~Hz}, 1 \mathrm{H}), 4.31$ (q, $J=7.2 \mathrm{~Hz}, 2 \mathrm{H}), 1.53(\mathrm{~s}, 6 \mathrm{H}), 1.41 \mathrm{ppm}(\mathrm{t}, J=7.2 \mathrm{~Hz}, 3 \mathrm{H}) ;{ }^{13} \mathrm{C} \mathrm{NMR}(100 \mathrm{MHz}$, $\left.\mathrm{CD}_{3} \mathrm{COCD}_{3}\right): \delta=177.1,170.0,147.3,143.4,129.4,126.8,125.8,124.4,124.1,118.1$, 113.5, 106.6, 96.8, 87.1, 42.5, 27.7, 13.4 ppm; IR (Nujol): $\bar{v}=2210(\mathrm{C} \equiv \mathrm{N}), 1723(\mathrm{C}=\mathrm{O})$, $1581(\mathrm{C}=\mathrm{C}), 1562 \mathrm{~cm}^{-1}(\mathrm{C}=\mathrm{C}) ; \operatorname{HRMS}\left(\mathrm{ESI}^{+}\right): \mathrm{m} / \mathrm{z}[\mathrm{M}+\mathrm{H}]^{+}$calcd for $\mathrm{C}_{19} \mathrm{H}_{19} \mathrm{~N}_{2} \mathrm{O}_{2} \mathrm{~S}$ 339.1162; found 339.1136; [M+Na $]^{+}$calcd for $\mathrm{C}_{19} \mathrm{H}_{18} \mathrm{~N}_{2} \mathrm{NaO}_{2} \mathrm{~S}$ 361.0981; found 361.0945; Anal. Calcd for $\mathrm{C}_{19} \mathrm{H}_{18} \mathrm{~N}_{2} \mathrm{O}_{2} \mathrm{~S}$ : C 67.43, H 5.36, N 8.28. Found: C 67.65, H 5.05, N 8.49.

\section{(Z)-5-((Z)-2-(3-ethylbenzothiazol-2(3H)-ylidene)ethylidene)-2-oxo-4-tert-butyl-2,5-}

dihydrofuran-3-carbonitrile (Bz0BuFu). Reaction time: 75 min. Eluent chromatography: $\mathrm{CH}_{2} \mathrm{Cl}_{2} / \mathrm{Et}_{2} \mathrm{O}$ 9.3:0.7. The solid obtained by flash chromatography was further washed with a mixture of pentane/ $\mathrm{CH}_{2} \mathrm{Cl}_{2}$ 8.5/1.5. Yield: purple-violet solid (8 mg; 15\%). Mp 265-268 ${ }^{\circ} \mathrm{C} ;{ }^{1} \mathrm{H}$ NMR (400 MHz, $\mathrm{CD}_{2} \mathrm{Cl}_{2}$ ): $\delta=7.55$ (dd, $\left.J_{1}=7.8 \mathrm{~Hz}, J_{2}=1.0 \mathrm{~Hz}, 1 \mathrm{H}\right), 7.42$ (ddd, $J_{1}$ $\left.=8.3 \mathrm{~Hz}, J_{2}=7.8 \mathrm{~Hz}, J_{3}=1.0 \mathrm{~Hz}, 1 \mathrm{H}\right), 7.23\left(\mathrm{td}, J_{1}=7.8 \mathrm{~Hz}, J_{2}=1.0 \mathrm{~Hz}, 1 \mathrm{H}\right), 7.18(\mathrm{~d}, J=$ $8.3 \mathrm{~Hz}, 1 \mathrm{H}), 7.03$ (d, $J=12.4 \mathrm{~Hz}, 1 \mathrm{H}), 6.11$ (d, $J=12.4 \mathrm{~Hz}, 1 \mathrm{H}), 4.13$ (q, $J=7.3 \mathrm{~Hz}, 2 \mathrm{H})$, 1.55 (s, 9H), $1.41 \mathrm{ppm}(\mathrm{t}, J=7.3 \mathrm{~Hz}, 3 \mathrm{H}) ;{ }^{13} \mathrm{C} \mathrm{NMR}$ : not registered due to its low solubility; IR (Nujol): $\bar{v}=2209(\mathrm{C} \equiv \mathrm{N}), 1720(\mathrm{C}=\mathrm{O}), 1591(\mathrm{C}=\mathrm{C}), 1531 \mathrm{~cm}^{-1}(\mathrm{C}=\mathrm{C})$; HRMS (ESI ${ }^{+}$): $m / z[\mathrm{M}+\mathrm{Na}]^{+}$calcd for $\mathrm{C}_{20} \mathrm{H}_{20} \mathrm{~N}_{2} \mathrm{NaO}_{2} \mathrm{~S}$ 375.1138; found 375.1140; Anal. Calcd for $\mathrm{C}_{20} \mathrm{H}_{20} \mathrm{~N}_{2} \mathrm{O}_{2} \mathrm{~S}$ : C 68.16, H 5.72, N 7.95. Found: C 68.34, H 5.42, N 7.80.

Compounds Bz1(PhFu,Me $\left.\mathbf{P}_{2} \mathbf{F u}, \mathrm{BuFu}\right)$. General procedure. To a solution of benzothiazolium salt Bz1 (334 mg; $0.70 \mathrm{mmol}$ ) and the corresponding acceptor 
(PhFu,Me $\mathbf{M} \mathbf{F u}, \mathbf{B u F u})(0.70 \mathrm{mmol})$ in ethanol $(7.5 \mathrm{~mL})$, triethylamine $(1.3 \mathrm{~mL}, 9.32 \mathrm{mmol})$ was added. The mixture was refluxed under argon with exclusion of light (TLC monitoring). After cooling, the resulting solid was isolated by filtration, washed with cold ethanol and a cold mixture of pentane/ $\mathrm{CH}_{2} \mathrm{Cl}_{2}$ 9.5/0.5 and finally purified by flash chromatography (silica gel) with $\mathrm{CH}_{2} \mathrm{Cl}_{2} / \mathrm{Et}_{2} \mathrm{O}$ 8:2 (9.2:0.8 for $\left.\mathbf{B z 1} \mathbf{M e}{ }_{2} \mathbf{F u}\right)$ as the eluent.

\section{(Z)-5-((2E,4Z)-4-(3-ethylbenzothiazol-2(3H)-ylidene)but-2-enylidene)-2-oxo-4-}

phenyl-2,5-dihydrofuran-3-carbonitrile (Bz1PhFu). Reaction time: 25 min. The solid obtained by flash chromatography was further washed with a mixture of pentane/ $\mathrm{CH}_{2} \mathrm{Cl}_{2}$ 7.5/2.5. Yield: Blue-green solid (81 mg; 29\%). Mp 272-275 ${ }^{\circ} \mathrm{C} ;{ }^{1} \mathrm{H}$ NMR (400 MHz, $\left.\mathrm{CD}_{2} \mathrm{Cl}_{2}\right): 7.63-7.54(\mathrm{~m}, 5 \mathrm{H}), 7.52(\mathrm{~d}, J=7.8 \mathrm{~Hz}, 1 \mathrm{H}), 7.39(\mathrm{t}, J=7.8 \mathrm{~Hz}, 1 \mathrm{H}), 7.19(\mathrm{t}, J=$ $7.8 \mathrm{~Hz}, 1 \mathrm{H}), 7.16-7.07$ (m, 2H), 6.64-6.53 (m, 2H), 5.96 (d, $J=12.2 \mathrm{~Hz}, 1 \mathrm{H}), 4.05$ (q, $J=$ $7.2 \mathrm{~Hz}, 2 \mathrm{H}), 1.39 \mathrm{ppm}(\mathrm{t}, J=7.2 \mathrm{~Hz}, 3 \mathrm{H}) ;{ }^{13} \mathrm{C}$ NMR: not registered due to its low solubility; IR (Nujol): $\bar{v}=2200(\mathrm{C} \equiv \mathrm{N}), 1729(\mathrm{C}=\mathrm{O}), 1556 \mathrm{~cm}^{-1}(\mathrm{C}=\mathrm{C})$; HRMS $\left(\mathrm{ESI}^{+}\right)$: $\mathrm{m} / \mathrm{z}[\mathrm{M}]^{+\cdot}$ calcd for $\mathrm{C}_{24} \mathrm{H}_{18} \mathrm{~N}_{2} \mathrm{O}_{2} \mathrm{~S}$ 398.1083; found 398.1084; $[\mathrm{M}+\mathrm{Na}]^{+}$calcd for $\mathrm{C}_{24} \mathrm{H}_{18} \mathrm{~N}_{2} \mathrm{NaO}_{2} \mathrm{~S}$ 421.0981; found 421.0981; Anal. Calcd for $\mathrm{C}_{24} \mathrm{H}_{18} \mathrm{~N}_{2} \mathrm{O}_{2} \mathrm{~S}$ : C 72.34, $\mathrm{H}$ 4.55, N 7.03. Found: C 72.51, H 4.34, N 6.93.

4-((2E,4Z)-4-(3-ethylbenzothiazol-2(3H)-ylidene)but-2-enylidene)-5,5-dimethyl-2oxo-2,5-dihydrofuran-3-carbonitrile $\left(\mathbf{B z 1 M e}_{2} \mathbf{F u}\right)$. Reaction time: 1 hour. A further purification by flash chromatography on reverse C18 silica gel, with acetonitrile/aqueous $\mathrm{CH}_{3} \mathrm{COONH}_{4} 15 \mathrm{mM}$ from 6:4 to 10:0 was needed. Yield: Deep blue solid (40 mg; 16\%). Mp 254-259 ${ }^{\circ} \mathrm{C} ;{ }^{1} \mathrm{H}$ NMR $\left(300 \mathrm{MHz}, \mathrm{CD}_{2} \mathrm{Cl}_{2}\right): \delta=7.63\left(\mathrm{dd}, J_{1}=14.6 \mathrm{~Hz}, J_{2}=11.7 \mathrm{~Hz}\right.$, 1H), $7.49\left(\mathrm{dd}, J_{1}=7.7 \mathrm{~Hz}, J_{2}=1.0 \mathrm{~Hz}, 1 \mathrm{H}\right), 7.34$ (ddd, $J_{1}=8.2 \mathrm{~Hz}, J_{2}=7.7 \mathrm{~Hz}, J_{3}=1.0$ $\mathrm{Hz}, 1 \mathrm{H}), 7.14\left(\mathrm{td}, J_{1}=7.7 \mathrm{~Hz}, J_{2}=1.0 \mathrm{~Hz}, 1 \mathrm{H}\right), 7.11(\mathrm{~d}, J=13.3 \mathrm{~Hz}, 1 \mathrm{H}), 7.05(\mathrm{~d}, J=8.2$ 
$\mathrm{Hz}, 1 \mathrm{H}), 6.22\left(\mathrm{dd}, J_{1}=13.3 \mathrm{~Hz}, J_{2}=11.9 \mathrm{~Hz}, 1 \mathrm{H}\right), 5.99(\mathrm{~d}, J=14.6 \mathrm{~Hz}, 1 \mathrm{H}), 5.78(\mathrm{~d}, J=$ $11.9 \mathrm{~Hz}, 1 \mathrm{H}), 3.99$ (q, $J=7.2 \mathrm{~Hz}, 2 \mathrm{H}), 1.56$ (s, 6H), $1.36 \mathrm{ppm}(\mathrm{t}, J=7.2 \mathrm{~Hz}, 3 \mathrm{H}) ;{ }^{13} \mathrm{C}$ NMR: not registered due to its low solubility; IR (Nujol): $\bar{v}=2213(\mathrm{C} \equiv \mathrm{N}), 1739(\mathrm{C}=\mathrm{O})$, 1651, $1581 \mathrm{~cm}^{-1}(\mathrm{C}=\mathrm{C})$; HRMS $\left(\mathrm{ESI}^{+}\right): \mathrm{m} / z[\mathrm{M}+\mathrm{Na}]^{+}$calcd for $\mathrm{C}_{21} \mathrm{H}_{20} \mathrm{~N}_{2} \mathrm{NaO}_{2} \mathrm{~S} 387.1138$; found 387.1144; Anal. Calcd for $\mathrm{C}_{21} \mathrm{H}_{20} \mathrm{~N}_{2} \mathrm{O}_{2} \mathrm{~S}$ : C 69.21, H 5.53, N 7.69. Found: C 69.10, H 5.41, N 7.80.

(Z)-4-tert-butyl-5-((2E,4Z)-4-(3-ethylbenzothiazol-2(3H)-ylidene)but-2-enylidene)-2oxo-2,5-dihydrofuran-3-carbonitrile (Bz1BuFu). Reaction time: 1 hour. Yield: Bluegreen solid (44 mg; 17\%). Mp 241-245 ${ }^{\circ} \mathrm{C} ;{ }^{1} \mathrm{H}$ NMR (400 MHz, THF-d 8 ): $\delta=7.51$ (dd, $J_{1}$ $\left.=7.8 \mathrm{~Hz}, J_{2}=1.2 \mathrm{~Hz}, 1 \mathrm{H}\right), 7.31\left(\mathrm{ddd}, J_{1}=8.2 \mathrm{~Hz}, J_{2}=7.4 \mathrm{~Hz}, J_{3}=1.2 \mathrm{~Hz}, 1 \mathrm{H}\right.$ ), 7.19 (dd, $\left.J_{1}=8.2 \mathrm{~Hz}, J_{2}=0.4 \mathrm{~Hz}, 1 \mathrm{H}\right), 7.13-7.05(\mathrm{~m}, 2 \mathrm{H}), 6.93\left(\mathrm{dd}, J_{1}=11.8 \mathrm{~Hz}, J_{2}=0.6 \mathrm{~Hz}, 1 \mathrm{H}\right)$, $6.52\left(\mathrm{dd}, J_{1}=13.6 \mathrm{~Hz}, J_{2}=11.8 \mathrm{~Hz}, 1 \mathrm{H}\right), 6.03(\mathrm{~d}, J=11.8 \mathrm{~Hz}, 1 \mathrm{H}), 4.08(\mathrm{q}, J=7.2 \mathrm{~Hz}$, 2H), 1.51 (s, 9H), $1.32 \mathrm{ppm}$ (t, $J=7.2 \mathrm{~Hz}, 3 \mathrm{H}) ;{ }^{13} \mathrm{C}$ NMR: not registered due to its low solubility; IR (Nujol): $\left.\quad \bar{v}=2191(\mathrm{C} \equiv \mathrm{N}), 1702(\mathrm{C}=\mathrm{O}), 1562 \mathrm{~cm}^{-1}(\mathrm{C}=\mathrm{C}) ; \mathrm{HRMS}_{(\mathrm{ESI}}{ }^{+}\right): \mathrm{m} / \mathrm{z}$ $[\mathrm{M}]^{+}$calcd for $\mathrm{C}_{22} \mathrm{H}_{22} \mathrm{~N}_{2} \mathrm{O}_{2} \mathrm{~S}$ 378.1397; found 378.1393; $[\mathrm{M}+\mathrm{Na}]^{+}$calcd for $\mathrm{C}_{22} \mathrm{H}_{22} \mathrm{~N}_{2} \mathrm{NaO}_{2} \mathrm{~S}$ 401.1294; found 401.1299; Anal. Calcd for $\mathrm{C}_{22} \mathrm{H}_{22} \mathrm{~N}_{2} \mathrm{O}_{2} \mathrm{~S}$ : C 69.81, $\mathrm{H}$ 5.86, N 7.40. Found: C 70.10, H 5.65, N 7.56.

Acknowledgments. We thank Dr. E. Galán (Delft University of Technology, The Netherlands) for helpful discussions. Financial support from MICINN-FEDER (CTQ201122727 and MAT2011-27978-C02-02), MINECO (CTQ2014-52331R) and Gobierno de Aragón-Fondo Social Europeo (E39 and E04) is gratefully acknowledged. Research at the Universidad de Málaga was supported by MINECO (CTQ2012-33733) and Junta de 
Andalucía (P09-4708). Authors would like to acknowledge the use of Servicio General de Apoyo a la Investigación-SAI, Universidad de Zaragoza.

Supporting Information Available. General experimental methods, NMR and UV-vis spectra of new compounds, NLO measurements, X-ray crystallographic data in CIF format and diagram of the crystal structures of Py0PhFu, Py1PhFu, Py1Me $\mathbf{F u}$ and $\mathbf{B z 0 P h F u}$, computed energies and Cartesian coordinates of optimized geometries, and contour plots of frontier molecular orbitals of all chromophores with the exception of Py1BuFu. This material is available free of charge via the Internet at http://pubs.acs.org.

\section{References and Footnotes}

(1) (a) Themed issue on Organic Nonlinear Optics: Marder, S. R. (Guest Ed.), J. Mater. Chem. 2009, 19 (40). (b) Dalton, L. R.; Sullivan, P. A.; Bale, D. H. Chem. Rev. 2010, 110, 25-55. (c) Stegeman, G. I.; Stegeman R. A. in Nonlinear Optics: Phenomena, Materials, and Devices, (Ed.: Boreman, G.), Wiley Series in Pure and Applied Optics, John Wiley \& Sons: Hoboken, 2012. (d) Coe, B. J. Coord. Chem. Rev. 2013, 257, 1438-1458. (e) Castet, F.; Rodriguez, V.; Pozzo, J.-L.; Ducasse, L.; Plaquet, A.; Champagne, B. Acc. Chem. Res. 2013, 46, 2656-2665.

(2) Bureš, F. RSC Adv. 2014, 4, 58826-58851, and references cited therein.

(3) (a) Marder, S. R.; Perry, J. W.; Tiemann, B. G.; Gorman, C. B.; Gilmour, S.; Biddle, S. L.; Bourhill, G. J. Am. Chem. Soc. 1993, 115, 2524-2526. (b) Bourhill, G.; Brédas, J.-L.; Cheng, L.-T.; Marder, S. R.; Meyers, F.; Perry, J. W.; Tiemann, B. G. J. Am. Chem. Soc. 1994, 116, 2619-2620. 
(4) (a) Marder, S. R.; Beratan, D. N.; Cheng, L.-T. Science 1991, 252, 103-106. (b)

Gorman, C. B.; Marder, S. R. Proc. Natl. Acad. Sci. USA 1993, 90, 11297-11301. (c) Meyers, F.; Marder, S. R.; Pierce, B. M.; Brédas, J.-L. J. Am. Chem. Soc. 1994, 116, 10703-10714. (d) Marder, S. R.; Gorman, C. B.; Meyers, F.; Perry, J. W.; Bourhill, G.; Brédas, J.-L.; Pierce, B. M. Science 1994, 265, 632-635.

(5) (a) Stiegman, A. E.; Graham, E.; Perry, K. J.; Khundkar, L. R.; Cheng, L.-T.; Perry, J. W. J. Am. Chem. Soc. 1991, 113, 7658-7666. (b) Cheng, L.-T.; Tam, W.; Marder, S. R.; Stiegman, A. E.; Rikken, G.; Spangler, C. W. J. Phys. Chem. 1991, 95, 10643-10652. (c) de Lucas, A. I.; Martín, N.; Sánchez, L.; Seoane, C.; Andreu, R.; Garín, J.; Orduna, J.; Alcalá, R.; Villacampa, B. Tetrahedron 1998, 54, 4655-4662. (d) Moreno-Mañas, M.; Pleixats, R.; Andreu, R.; Garín, J.; Orduna, J.; Villacampa, B.; Levillain, E.; Sallé, M. J. Mater. Chem. 2001, 11, 374-380. (e) González, M.; Segura, J. L.; Seoane, C.; Martín, N.; Garín, J.; Orduna, J; Alcalá, R.; Villacampa, B.; Hernández V.; López Navarrete, J. T. J. Org. Chem. 2001, 66, 8872-8882.

(6) The term "butenolide" for describing buteno- or crotonolactones was first employed by Klobb in 1898: Klobb, T. Bull. Soc. Chim. Fr. 1898, 389. Though the butenolide nomenclature has been in vogue for quite sometime, Chemical Abstracts currently has adopted the furanone system for naming these compounds. Thus, $\Delta^{\alpha, \beta}$-butenolides are 2(5H)-furanones. In this article, the terms butenolide/furanone will be used interchangeably.

(7) (a) Rao, Y. S. Chem. Rev. 1976, 76, 625-694. (b) Carter, N. B.; Nadany, A. E.; Sweeny, J. B. J. Chem. Soc., Perkin Trans. 1 2002, 2324-2342. (c) Ugurchieva, T. M.; Veselovsky, V. V. Russ. Chem. Rev. 2009, 78, 337-373. 
(8) (a) Wang, P.; Chang, Y.; Xu, Y.; Ye, C. Proc. SPIE-Int. Soc. Opt. Eng. 1998, 3556,

73-83. (b) Asthana, D.; Ajayakumar, M. R.; Pant, R. P.; Mukhopadhyay, P. Chem. Commun. 2012, 48, 6475-6477.

(9) (a) Zhang, C.; Dalton, L. R.; Oh, M.-C.; Zhang, H.; Steier, W. H. Chem. Mater. 2001, 13, 3043-3050. (b) Liao, Y.; Eichinger, B. E.; Firestone, K. A.; Haller, M.; Luo, J.; Kaminsky, W.; Benedict, J. B.; Reid, P. J.; Jen, A. K-Y; Dalton, L. R.; Robinson, B. H. J. Am. Chem. Soc. 2005, 127, 2758-2766.

(10) Selected examples for 4H-pyranylidene-containing chromophores: (a) Faux, N.; Caro, B.; Robin-le Guen, F.; Le Poul, P.; Nakatani, K.; Ishow, E. J. Organomet. Chem. 2005, 690, 4982-4988. (b) Andreu, R.; Carrasquer, L.; Franco, S.; Garín, J.; Orduna, J.; Martínez de Baroja, N.; Alicante, R.; Villacampa, B.; Allain, M. J. Org. Chem. 2009, 74, 6647-6657. (c) Andreu, R.; Galán, E.; Orduna, J.; Villacampa, B.; Alicante, R.; López Navarrete, J. T.; Casado, J.; Garín, J. Chem. -Eur. J. 2011, 17, 826-838. (d) Achelle, S.; Malval, J.-P.; Aloïse, S.; Barsella, A.; Spangenberg, A.; Mager, L.; Akdas-Kilig, H.; Fillaut, J.-L.; Caro, B.; Robin-le Guen, F. ChemPhysChem 2013, 14, 2725-2736. (e) Marco, A. B.; Martínez de Baroja, N.; Franco, S.; Garín, J.; Orduna, J.; Villacampa, B.; Revuelto, A.; Andreu, R. Chem. Asian J. 2015, 10, 188-197.

(11) Selected examples: (a) Ashwell, G. J.; Malhotra, M.; Bryce, M. R.; Grainger, A. M.; Synth. Met. 1991, 41-43, 3173-3176. (b) Kay, A. J.; Woolhouse, A. D.; Gainsford, G. J.; Haskell, T. G.; Barnes, T. H.; McKinnie, I. T.; Wyss, C. P. J. Mater. Chem. 2001, 11, 9961002. (c) Kay, A. J.; Woolhouse, A. D.; Zhao, Y.; Clays, K. J. Mater. Chem. 2004, 14, 1321-1330. (d) Latorre, S.; Moreira, I. de P. R.; Villacampa, B.; Julià, L.; Velasco, D.; Bofill, J. M.; López-Calahorra, F. ChemPhysChem 2010, 11, 912-919. (e) Andreu, R.; 
Galán, E.; Garín, J.; Orduna, J.; Alicante, R.; Villacampa, B. Tetrahedron Lett. 2010, 51, 6863-6866.

(12) Selected examples: (a) Coe, B. J.; Harris, J. A.; Hall, J. J.; Brunschwig, B. S.; Hung, S.-T.; Libaers, W.; Clays, K.; Coles, S. J.; Horton, P. N.; Light, M. E.; Hursthouse, M. B.; Garín, J.; Orduna, J. Chem. Mater. 2006, 18, 5907-5918. (b) Hrobárik, P.; Sigmundová, I.; Zahradník, P.; Kasák, P.; Arion, V.; Franz, E.; Clays, K. J. Phys. Chem. C 2010, 114, 22289-22302. (c) Hrobárik, P.; Hrobáriková, V.; Sigmundová, I.; Zahradník, P.; Fakis, M.; Polyzos, I.; Persephonis, P. J. Org. Chem. 2011, 76, 8726-8736. (d) Raposo, M. M. M.; Castro, M. C. R.; Belsley, M.; Fonseca, A. M. C. Dyes Pigm. 2011, 91, 454-465.

(13) Hrobárik, P.; Zahradník, P.; Fabian, W. M. F. Phys. Chem. Chem. Phys. 2004, 6, 495-502.

(14) Acceptor PhFu: Ford, J. A. Jr.; Wilson, C. V.; Young, W. R. J. Org. Chem. 1967, 32, $173-177$.

(15) Acceptor $\mathbf{M e}_{2}$ Fu: (a) Cheikh, N.; Villemin, D.; Bar, N.; Lohier, J.-F.; ChoukchouBraham, N.; Mostefa-Kara, B.; Sopkova, J. Tetrahedron 2013, 69, 1234-1247. (b) For this work acceptor $\mathbf{M e}_{2} \mathbf{F u}$ was prepared by following the same procedure reported for the corresponding analogue with methyl and ethyl groups in C5: Maheut, G.; Liao, L.; Catel, J.-M.; Jaffrès, P.-A.; Villemin, D. J. Chem. Ed. 2001, 78, 654-657.

(16) Acceptor BuFu: Erdmann, D.; Schuehrer, K.; Koch, W.; Schneider, G. Patent DE 2116416, 1972; Chem. Abstr. 1973, 78, 16015.

(17) Andreu, R.; Galán, E.; Garín, J.; Herrero, V.; Lacarra, E.; Orduna, J.; Alicante, R.; Villacampa, B. J. Org. Chem. 2010, 75, 1684-1692.

(18) See for example: (a) Alías, S.; Andreu, R.; Blesa, M. J.; Cerdán, M. A.; Franco, S.; Garín, J.; López, C.; Orduna, J.; Sanz, J.; Alicante, R.; Villacampa, B.; Allain, M. J. Org. 
Chem. 2008, 73, 5890-5898. (b) Marco, A. B.; Andreu, R.; Franco, S.; Garín, J.; Orduna, J.; Villacampa, B.; Alicante, R. Tetrahedron 2013, 69, 3919-3926.

(19) (a) Coe, B. J.; Harris, J. A.; Asselberghs, I.; Wostyn, K.; Clays, K.; Persoons, A.;

Brunschwing, B. S.; Coles, S. J.; Gelbrich, T.; Light, M. E.; Hursthouse, M. B.; Nakatani, K. Adv. Funct. Mater. 2003, 13, 347-357. (b) Beverina, L.; Fu, J.; Leclercq, A.; Zojer, E.; Pacher, P.; Barlow, S.; van Stryland, E. W.; Hagan, D. J.; Brédas, J.-L.; Marder, S. R. J. Am. Chem. Soc. 2005, 127, 7282-7283.

(20) Brooker, L. G. S.; White, F. L.; Keyes, G. H.; Smyth, C. P.; Oesper, P. F. J. Am. Chem. Soc. 1941, 63, 3192-3203.

(21) (a) Dehu, C.; Meyers, F.; Brédas, J.-L. J. Am. Chem. Soc. 1993, 115, 6198-6206. (b) Hilger, A.; Gisselbrecht, J.-P.; Tykwinski, R. R.; Boudon, C.; Schreiber, M.; Martin, R. E.; Lüthi, H. P.; Gross, M.; Diederich, F. J. Am. Chem. Soc. 1997, 119, 2069-2078.

(22) Bird, C. W. Tetrahedron 1986, 42, 89-92.

(23) Marco, A. B.; Mayorga Burrezo, P.; Mosteo, L.; Franco, S.; Garín, J.; Orduna, J.; Diosdado, B. E.; Villacampa, B.; López Navarrete, J. T.; Casado, J.; Andreu, R. RSC Adv. 2015, 5, 231-242.

(24) Chasseau, D.; Gaultier, J.; Hauw, C.; Fugnitto, R.; Gianis, V.; Strzelecka, H. Acta Crystallogr., Sect. B: Struct. Crystallogr. Cryst. Chem. 1982, 38, 1629-1631.

(25) Marder, S. R.; Cheng, L.-T.; Tiemann, B. G.; Friedli, A. C.; Blanchard-Desce, M.; Perry, J. W.; Skindhøj, J. Science 1994, 263, 511-514.

(26) Chang, Y. M. Huaxue Tongbao 1996, 10, 58-60.

(27) Poronik, Y. M.; Hugues, V.; Blanchard-Desce, M.; Gryko, D. T. Chem. -Eur. J. 2012, 18, 9258-9266. 
(28) (a) Marder, S. R.; Perry, J. W.; Bourhill, G.; Gorman, C. B.; Tiemann, B. G.; Mansour, K. Science 1993, 261, 186-189. (b) For all-trans polyenes $\Delta J \sim 6.0 \mathrm{~Hz}$ and for cyanines $\Delta J=0$ Hz: Scheibe, G.; Seiffert, W.; Hohlneicher, G.; Jutz, C.; Springer, H. J. Tetrahedron Lett. 1966, 7, 5053-5059.

(29) Kulinich, A. V.; Ishchenko, A. A.; Groth, U. M. Spectrochim. Acta, Part A 2007, 68, 6-14.

(30) (a) Brooker, L. G. S.; Sklar, A. L.; Creesman, H. W. J.; Keyes, G. H.; Smith, L. A.; Sprague, R. H.; Van Lare, E.; Van Zandt, G.; White, F. L.; Williams, W. W. J. Am. Chem. Soc. 1945, 67, 1875-1889. (b) Bricks, J. L.; Kachkovskii, A. D.; Slominskii, Yu. L.; Gerasov, A. O.; Popov, S. V. Dyes Pig. 2015, 121, 238-255.

(31) Casado, J.; Moreno Oliva, M.; Ruiz Delgado, M. C.; López Navarrete, J. T.; Sánchez, L.; Martín, N.; Andreu, R.; Carrasquer, L.; Garín, J.; Orduna, J. J. Chem. Phys. 2007, 126, 074701-1-074701-8.

(32) (a) Inoue, S.; Aso, Y.; Otsubo, T. Chem. Commun. 1997, 1105-1106. (b) Milián, B.; Ortí, E.; Hernández, V.; López Navarrete, J. T.; Otsubo, T. J. Phys. Chem. B 2003, 107, 12175-12183. (c) Kang, H.; Facchetti, A.; Jiang, H.; Cariati, E.; Righetto, S.; Ugo, R.; Zuccaccia, C.; Macchioni, A.; Stern, C. L.; Liu, Z.; Ho, S.-T.; Brown, E. C.; Ratner, M. A.; Marks, T. J. J. Am. Chem. Soc. 2007, 129, 3267-3286.

(33) This effect is well known as "vinylene shift", see for example: Kachkovski, A. D.; Kovalenko, N. M. Dyes Pig. 1997, 35, 131-148.

(34) Kurdyukov, V. V.; Ishchenko, A. A.; Kudinova, M. A.; Tolmachev, A. I. Chem. Hetetocyclic Comp. 1987, 23, 628-633.

(35) Ikeda, H.; Sakai, T.; Kawasaki, K. Chem. Phys. Lett. 1991, 179, 551-554. 
(36) This behavior has already been reported for others D- $\pi$-A systems: (a) Ref. 23. (b) Kim, O.-K.; Fort, A.; Barzoukas, M.; Blanchard-Desce, M.; Lehn, J.-M. J. Mater. Chem. 1999, 9, 2227-2232. (c) Davies, J. A.; Elangovan, A.; Sullivan, P. A.; Olbricht, B. C.; Bale, D. H.; Ewy, T. R.; Isborn, C. M.; Eichinger, B. E.; Robinson, B. H.; Reid, P. J.; Li, X.; Dalton, L. R. J. Am. Chem. Soc. 2008, 130, 10565-10575. (d) Marco, A. B.; Andreu, R.; Franco, S.; Garín, J.; Orduna, J.; Villacampa, B.; Diosdado, B. E.; López Navarrete, J. T.; Casado, J. Org. Biomol. Chem. 2013, 11, 6338-6349.

(37) (a) Oudar, J. L.; Chemla, D. S. J. Chem. Phys. 1977, 66, 2664-2668. (b) Kanis, D. R.; Ratner, M. A.; Marks, T. J. Chem. Rev. 1994, 94, 195-242.

(38) Faux, N.; Robin-le Guen, F.; Le Poul, P.; Caro, B.; Nakatani, K.; Ishow, E.; Golhen, S. Eur. J. Inorg. Chem. 2006, 3489-3497.

(39) Cho, B. R.; Je, J. T.; Lee, S. J.; Lee, S. H.; Kim, H. S.; Jeon, S. J.; Song, O.-K.; Wang, C. H. J. Chem. Soc. Perkin Trans. 2 1996, 2141-2144. 